\title{
Evolution of the gyrB gene and the molecular phylogeny of Enterobacteriaceae: a model molecule for molecular systematic studies
}

Unité Des Entérobactéries, Unité INSERM 389, Institut Pasteur, 28 rue du Docteur Roux, 75724 Paris Cedex 15, France

\author{
Catherine Daugat \\ Tel: +33 1456887 46. Fax: +331406130 07. e-mail: cdauga@pasteur.fr
}

Keywords: gyrB, 16S rRNA, Enterobacteriaceae, evolutionary systematic studies

\section{INTRODUCTION}

The enteric bacteria belonging to the Enterobacteriaceae family are of special microbiological interest because of their pathogenic and non-pathogenic relationships with the human gastrointestinal tract. Some Enterobacteriaceae are also plant or animal pathogens and are responsible for substantial economic losses in agriculture (Brenner, 1981). This high diversity of

\footnotetext{
† Present address: Collection de l'Institut Pasteur, Institut Pasteur, 25 rue du Docteur Roux, 75724 Paris Cedex 15, France.

Abbreviations: GCIII, third codon position $\mathrm{G}+\mathrm{C}$; RSCU, relative synonymous codon usage.

The EMBL accession numbers of the gyrB sequences are AJ300528AJ300554.
}

hosts correlates with a wide phenotypic diversity. There are currently over 35 genera described in this family (Brenner, 1984; Farmer et al., 1985; HickmanBrenner et al., 1985; Gherna, 1991; Hauben et al., 1998).

When investigating the environmental distribution of Enterobacteriaceae, it must be remembered that it is not always possible to culture natural populations of bacteria by standard techniques (Amann et al., 1995). They may be viable but non-culturable cells because their physiological capacities have been modified. This has been described for Photorhabdus (Xenorhabdus) luminescens, Escherichia coli $\mathrm{O} 157: \mathrm{H} 7$ and Salmonella typhi (Morgan et al., 1997; Tanaka et al., 2000; Cho \& Kim, 1999). Evolutionary systematics which classify bacteria naturally can be used to identify these difficult 
to culture organisms (Debabov, 1999; Dore et al., 1998; Vuddhakul et al., 2000). However, lineages must be placed in their correct evolutionary position before gene sequence analysis of clades can reliably identify organisms (Ludwig et al., 1998).

Phylogenetic studies on Enterobacteriaceae and other prokaryotes have used rRNA sequences (Fox, 1980; Olsen et al., 1986; Woese, 1987). Comparison of the 16S rRNA gene sequences of Serratia, Yersinia, Salmonella, Photorhabdus and Erwinia have demonstrated that this molecule can discriminate between closely related species (Dauga et al., 1990; Ibrahim et al., 1993; Christensen et al., 1998; Liu et al., 1997). The phylogenetic analysis of 16S rRNA gene sequences showed four emerging clusters of phytopathogens within the Enterobacteriaceae (Hauben et al., 1998). However, unlike DNA hybridization studies (Brenner, 1984) and phenotypic classification, 16S rRNA studies found that Klebsiella, Enterobacter and Serratia genera are polyphyletic (Hauben et al., 1998; Spröer et al., 1999).

Protein-encoding gene sequences have also been used to describe the phylogenetic relationships of Enterobacteriaceae. Unfortunately, in spite of a higher phylogenetic resolution than that obtained from $16 \mathrm{~S}$ rRNA sequences (Yamamoto \& Harayama, 1996), the phylogenetic trees obtained were not totally consistent with the classical taxonomy. The sequences of gap genes, which encode glyceraldehyde-3-phosphate dehydrogenase, and omp $A$, which encodes outer-membrane protein 3A, revealed that five species of Escherichia do not form a monophyletic group (Lawrence et al., 1991). The sequences of $\operatorname{rec} A$, a gene involved in recombination and DNA repair, showed that Shigella strains cannot be phylogenetically separated from Escherichia coli (Lloyd \& Sharp, 1993). The groE sequences, which encode stress proteins, indicated that the members of genera Enterobacter, Pantoea and Klebsiella were closely related to each other and did not form distinct phylogenetic groups (Harada \& Ishikawa, 1997). The partial sequence of rpoB, the gene encoding the RNA polymerase $\beta$-subunit, and the partial sequence of inf $B$, the gene encoding translation initiation factor 2, also suggested that Klebsiella is a polyphyletic genus (Mollet et al., 1997; Hedegaard et al., 1999).

Recently, the $\operatorname{gyr} B$ gene was proposed as a suitable phylogenetic marker for the identification and classification of bacteria (Yamamoto \& Harayama, 1996; Yamamoto et al., 1999). gyrB is a single-copy gene, present in all bacteria, which encodes the ATPase domain of DNA gyrase, an enzyme essential for DNA replication (Huang, 1996). The amino acid sequences of GyrB are conservative enough to allow the comparison of taxa which are not closely related (Yamamoto \& Harayama, 1996; Huang, 1996). The phylogenetic analyses of gyrB nucleotide sequences also reflected the evolutionary relationships of closely related species such as in the Acinetobacter
(Yamamoto et al., 1999), Pseudomonas (Yamamoto \& Harayama, 1998), Shewanella (Venkateswaran et al., 1999) and Micromonospora (Kasai et al., 2000) genera. In addition, $\operatorname{gyr} B$ sequence analyses also distinguished Pseudomonas putida strains (Yamamoto \& Harayama, 1995), slowly growing mycobacterial species (Kasai et al., 2000), Vibrio parahaemolyticus from Vibrio alginolyticus (Venkateswaran et al., 1998), and Bacillus cereus from Bacillus mycoides, Bacillus thuringiensis and Bacillus anthracis (Yamada et al., 1999).

In this study I investigated the reliability and usefulness of $g y r B$ gene sequences for the phylogenetic analysis of Enterobacteriaceae. The gyrB-based phylogenetic trees were compared to $16 \mathrm{~S}$ rRNA gene (16S rDNA) sequence trees for the whole Serratia genus, two species each of Proteus, Enterobacter and Klebsiella and seven other species belonging to seven other genera of Enterobacteriaceae.

gyr $B$ partial sequence analysis proved to be more reliable and useful than $16 \mathrm{~S}$ rDNA for determining the evolutionary relationships of Serratia species. However, many discrepancies occurred between the classic descriptions of genera and monophyletic groups obtained with $\operatorname{gyr} B$ phylogenetic trees for Enterobacter and Klebsiella species. Therefore, (i) I determined whether saturation and/or long-branch-attracting phenomena distorted the gyr $B$ phylogenetic trees, and (ii) codon usage and base composition analyses of genes were used to determine whether genetic transfer occurred in some lineages. Knowledge of some of these phylogenetic construction biases and natural events allowed me to determine when the evolution of the gyr $B$ genes best reflected the phylogenetic relationships of species within the Enterobacteriaceae.

\section{METHODS}

Bacterial strains. The strains used in this study are listed in Table 1.

$16 S$ rRNA data. Several 16S rRNA sequences are available in GenBank and EMBL databases: Citrobacter freundii (accession no. M59291; unpublished), Escherichia coli (X80725; Cilia et al., 1996), Enterobacter aerogenes (AB004750; Harada et al., 1996), Enterobacter cloacae (AJ251469; unpublished), Pectobacterium carotovorum (Erwinia carotovora) (M59149; unpublished), Hafnia alvei (M59155; unpublished), Haemophilus influenzae (M35019 and M59433; unpublished), Klebsiella pneumoniae (X87276; Ludwig et al., 1995), Klebsiella terrigena (Y17658; unpublished), Plesiomonas shigelloides (M59159; unpublished) and Salmonella typhimurium (X80681; Cilia et al., 1996). Nine Serratia spp. 16S rRNA sequences were also recovered from international databases (AJ233427, AJ233428, AJ233429, AJ233430, AJ233431，AJ233432，AJ233433, AJ233434, AJ233436; Spröer et al., 1999). Recently, I published the 16S rRNA gene sequences from Proteus mirabilis (AJ301682), Proteus vulgaris (AJ301683), Morganella morganii (AJ301681) and Providencia alcalifaciens (AJ301684) in the EMBL database.

Chromosomal DNA isolation. Each bacterial sample was grown aerobically in Trypto-casein soy broth (Sanofi Diag- 
Table 1. Strains and gyrB sequences used in this study

\begin{tabular}{|c|c|c|c|}
\hline Species & Strain* & Characteristics & Accession no. \\
\hline Citrobacter freundii & $\operatorname{CIP} 57.32^{\mathrm{T}}=\mathrm{ATCC} 8090^{\mathrm{T}}$ & & AJ300528 \\
\hline Enterobacter aerogenes & CIP $60.86^{\mathrm{T}}=\mathrm{ATCC} 13048^{\mathrm{T}}$ & & AJ300554 \\
\hline Enterobacter cloacae & CIP $60.85^{\mathrm{T}}=\mathrm{ATCC} 13047^{\mathrm{T}}$ & & AJ300553 \\
\hline Hafnia alvei & $\operatorname{CIP} 57.31^{\mathrm{T}}=\mathrm{ATCC} 13337^{\mathrm{T}}$ & Biotype 1 & AJ300551 \\
\hline Klebsiella pneumoniae & $\operatorname{CIP} 82.91^{\mathrm{T}}=\mathrm{ATCC} 13883^{\mathrm{T}}$ & Subsp. pneumoniae & AJ300550 \\
\hline Klebsiella terrigena & $\operatorname{CIP} 80.7^{\mathrm{T}}=\operatorname{ATCC} 33257^{\mathrm{T}}$ & & AJ300549 \\
\hline Morganella morganii & CIP $\mathrm{A} 231^{\mathrm{T}}=\mathrm{ATCC} 25830^{\mathrm{T}}$ & & AJ300548 \\
\hline Pectobacterium carotovorum & $\operatorname{CIP} 82.83^{\mathrm{T}}=\mathrm{ATCC} 15713^{\mathrm{T}}$ & Subsp. carotovorum & AJ300552 \\
\hline Plesiomonas shigelloides & CIP $63.5^{\mathrm{T}}=$ ATCC $14029^{\mathrm{T}}$ & & AJ300545 \\
\hline Proteus mirabilis & CIP $103181^{\mathrm{T}}=$ ATCC $29906^{\mathrm{T}}$ & & AJ300546 \\
\hline Proteus vulgaris & CIP $58.60^{\mathrm{T}}=$ ATCC $13315^{\mathrm{T}}$ & & AJ300544 \\
\hline Providencia alcalifaciens & CIP $82.90^{\mathrm{T}}=$ ATCC $9886^{\mathrm{T}}$ & & AJ300547 \\
\hline Salmonella enterica & CIP $60.62^{\mathrm{T}}=$ ATCC $43971^{\mathrm{T}}$ & Subsp. enterica serotype Typhimurium & AJ300529 \\
\hline Serratia entomophila & CIP $102919^{\mathrm{T}}=$ ATCC $43705^{\mathrm{T}}$ & Biotype 1 & AJ300543 \\
\hline Serratia entomophila & $\mathrm{A} 15 \dagger$ & Biotype 2 & AJ300542 \\
\hline Serratia ficaria & CIP $79.23^{\mathrm{T}}=\mathrm{ATCC} 33105^{\mathrm{T}}$ & O-type 1 & AJ300541 \\
\hline Serratia ficaria & $\mathrm{G} 4037 \dagger$ & O-type 2 & AJ300540 \\
\hline Serratia fonticola & CIP $78.64^{\mathrm{T}}=$ ATCC $29844^{\mathrm{T}}$ & & AJ300539 \\
\hline Serratia grimesii & CIP $103361^{\mathrm{T}}=$ ATCC $14460^{\mathrm{T}}$ & & AJ300538 \\
\hline Serratia liquefaciens & CIP $103238^{\mathrm{T}}=$ ATCC 27592 & & AJ300537 \\
\hline Serratia marcescens & CIP $103235^{\mathrm{T}}=$ ATCC $13880^{\mathrm{T}}$ & Biotype A2a & AJ300536 \\
\hline Serratia marcescens & G3770† & Biotype A6a & AJ300535 \\
\hline Serratia marcescens & $\mathrm{G} 81 \uparrow$ & Biotype TCT & AJ300534 \\
\hline Serratia odorifera & $\operatorname{CIP} 79.1^{\mathrm{T}}=$ ATCC $33077^{\mathrm{T}}$ & & AJ300533 \\
\hline Serratia plymuthica & CIP $103239^{\mathrm{T}}=$ ATCC $183^{\mathrm{T}}$ & & AJ300532 \\
\hline Serratia proteamaculans & CIP $103236^{\mathrm{T}}=$ ATCC $19323^{\mathrm{T}}$ & Biotype C1c & AJ300531 \\
\hline Serratia rubidaea & CIP $103234^{\mathrm{T}}=$ ATCC $27593^{\mathrm{T}}$ & & AJ300530 \\
\hline
\end{tabular}

* CIP, Collection Institut Pasteur, Paris, France; ATCC, American Type Culture Collection, Manassas, VA, USA.

$\dagger$ From the collection of P. A. D. Grimont, Institut Pasteur, Paris, France.

nostics Pasteur), with shaking, at $37^{\circ} \mathrm{C}$. Chromosomal DNA was isolated as described previously (Dauga et al., 1998).

GyrB gene amplification. The following primers were used to amplify gyr $B$ : gyr-320, 5'-TAARTTYGAYGAYAACTCYTAYAAAGT-3' $(\mathrm{R}=\mathrm{A}$ or $\mathrm{G}$; $\mathrm{Y}=\mathrm{C}$ or $\mathrm{T})$; rgyr-1260, 5'-CMCCYTCCACCARGTAMAGTTC-3' (M = A or C). Primer gyr-320 annealed at positions 306-332 and primer rgyr-1260 annealed at positions 1276-1255 (Escherichia coli numbering; Adachi et al., 1987). These primers were selected on the basis of gyrB sequence conservation in Escherichia coli (accession numbers X04341 and X00870; Adachi et al., 1987), Proteus mirabilis (M58352 and M31295; Skovgaard, 1990), Pseudomonas putida (D37926 and X54631; Yamamoto \& Harayama, 1995; Parales \& Harwood, 1990) and Haemophilus influenzae (L45208 and L42023; Fleischmann et al., 1995) from the $\gamma$-subclass of the Proteobacteria. The gyr-320 primer annealed at the ATP binding site of the gyrB subunit (Wang, 1996). The rgyr-1260 primer annealed to part of the topoisomerase II region used to define the consensus pattern [LIVMA]-x-E-G, which recognizes the DNA topoisomerase II family in the PROSITE database (Bairoch et al., 1997). Primer specificity was checked against the parE sequence (topoisomerase IV) of Escherichia coli (M58409 and M37833; Kato et al., 1990). Computer analysis using the FASTA algorithm (Pearson \&
Lipman, 1988) on the GenBank and EMBL databases confirmed that the selected primers should not amplify topoisomerase IV sequences or other coding sequences. The reaction mixture $(100 \mu \mathrm{l})$ contained $10 \mathrm{mM}$ Tris $/ \mathrm{HCl}$ (pH 8.3), $50 \mathrm{mM} \mathrm{KCl}, 2.5 \mathrm{mM} \mathrm{MgCl}_{2}, 0.01 \%$ gelatin, $0.2 \mathrm{mM}$ each dNTP (Pharmacia Biotech), $50 \mathrm{pmol}$ each primer, $1.25 \mathrm{U}$ Hi-Taq polymerase (Bioprobe) and $1 \mu \mathrm{l}$ DNA. The mixture was overlaid with $50 \mu \mathrm{l}$ mineral oil (Sigma). PCR amplification was carried out in a PTC-100 thermal Cycler (MJ Research) as follows: $94{ }^{\circ} \mathrm{C}$ for $4 \mathrm{~min}$, followed by 35 cycles of $94^{\circ} \mathrm{C}$ for $1 \mathrm{~min}, 55^{\circ} \mathrm{C}$ for $1 \mathrm{~min}$ and $72{ }^{\circ} \mathrm{C}$ for $2 \mathrm{~min}$, with a final incubation at $72^{\circ} \mathrm{C}$ for $10 \mathrm{~min}$. Amplification products were examined by standard agarose gel electrophoresis $(0.8 \%)$ and ethidium bromide staining. A $1 \mathrm{~kb}$ DNA ladder (Gibco-BRL) was used as a molecular size marker.

gyrB gene cloning and sequencing. To facilitate cloning a 12-base dUMP-containing sequence (CUACUACUACUA) was added to the $5^{\prime}$ end of PCR primers (Rashtchian et al., 1992). The CLONAMP System (Gibco-BRL) was used to clone the resulting PCR product into pAMP1, and this was subsequently used to transform Escherichia coli MC1061. The presence of the insert in five clones was checked by restriction analysis with BamHI and EcoRI (Amersham International). Two clones per sample were sequenced by use of the thermosequenase core sequencing kit, with 7- 
deaza-dGTP and universal primers complementary to plasmid, on a Vistra DNA Sequencer (Amersham). The following primers were used for sequencing: gyr-550, 5'-GAATTCGARTACGATATTYTGG-3', and rgyr-550 which annealed at positions 541-562; gyr-670S, 5'-AAGGCGGYRTCMRKGC-3' $(\mathrm{K}=\mathrm{G}$ or $\mathrm{T})$, and rgyr-670S at positions 656-671; gyr-670P, 5'-GAAGGYGGTATYMARGCRTT-3', and rgyr-670P at positions 655-674; gyr-860, 5'-CATKGCSGYRSGGAARCC-3' (S=G or C), and rgyr-860 at positions 850-867; and gyr-1010, 5'-AAGACAAACTGGTTTCTTCCGA-3', and rgyr-1010 at positions 1010-1031 (Escherichia coli numbering system). The EMBL accession numbers of the $\operatorname{gyr} B$ sequences determined are given in Table 1.

Phylogenetic data analysis. The CLUSTAL V algorithm (Higgins, 1994) of the MegAlign program in the Lasergene software package (DNAStar, Madison, WI) was used to make initial alignments with default gap penalties. The initial alignments were further refined by eye, introducing gaps to improve the overall alignment, and by use of the alignment editor of the PAUP* version 4.0 software package (Swofford, 1998). Sequence distance matrices were established in pairwise comparisons by use of the Kimura algorithm (Kimura, 1980). Phylogenetic trees were constructed by the neighbour-joining method (Saitou \& Nei, 1987) using the PHYLIP version 3.5 software package (Felsenstein, 1993). Parsimony analysis was carried out with maximum-parsimony implemented in the PAUP* 4.0 software package. Maximum-parsimony trees were obtained by 100 random addition heuristic search replicates and the tree bisection-reconnection branch-swapping option. A maximum-likelihood analysis was also done with PAUP* version 4.0 with a transition/transversion ratio of 1.5 for both $16 \mathrm{~S}$ rDNA and $\operatorname{gyr} B$ genes with and without a gamma distribution for rate variation among sites (Felsenstein, 1981; Olsen et al., 1994). Statistical significance was evaluated by bootstrap analysis (Felsenstein, 1985) with 100 repeats of bootstrap samplings.

Saturation test. Saturation was detected graphically by plotting sequence differences between pairs of taxa against the estimated number of substitutions between sequences (Griffiths, 1997). The sequence differences between pairs of taxa corresponded to the observed proportion of positions that are not shared by two taxa (uncorrected distance). The estimated numbers of substitutions per site between all pairs of taxa on trees used in this study were derived from the parsimony method and obtained using the PAUP* 4.0 package. Parsimony branch lengths were derived from the accelerated transformation (ACCTRAN) method in this program. Data were considered saturated when a logarithmic curve, ending in a plateau, provided a better fit than a linear regression.

Codon usage analysis. Genome composition bias, which generates a bias in degenerate positions of coding sequences, and selection of specific codons to increase translation efficiency contribute to codon usage bias (Morton, 1998). In every species in which codon usage has been analysed, there is a species-specific codon usage preference (Grantham et al., 1981). Thus, genes with an unusual codon usage were probably acquired by lateral transfer (Médigue et al., 1991). The relative synonymous codon usage (RSCU) values of the gyr $B$ genes of all the species were calculated using CodonW software (written by John Peden and available from http: //www.molbiol.ox.ac.uk/cu). The RSCU value for a codon is calculated by dividing the observed frequency of that codon by the frequency that would be expected if each codon encoding a particular amino acid was used equally (Sharp \& $\mathrm{Li}, 1987)$. Thus RSCU data minimize the effects of amino acid composition. To investigate the major trends in codon usage in different species, CodonW was used to carry out a correspondence analysis. This resulted in a point in the codon space for each species, the positions of which sometimes suggested codon usage bias.

Synonymous and non-synonymous substitutions. In molecular evolutionary studies nucleotide substitutions can be divided into two classes: synonymous substitutions, which do not change the amino acid, and non-synonymous substitutions, which result in an amino acid replacement. Most non-synonymous substitutions are typically eliminated by purifying selection, which leads to a predominance of synonymous substitutions. When positive Darwinian selection occurs, non-synonymous substitutions become more frequent. Thus, the relative rates of synonymous and nonsynonymous substitutions are good indicators of the amount and type of selection affecting a gene (Sharp, 1997). I estimated the numbers of synonymous substitutions per synonymous site $\left(d_{\mathrm{s}}\right)$ and non-synonymous substitutions per non-synonymous site $\left(d_{\mathrm{N}}\right)$ by using the method of Nei \& Gojobori (1986) in the PAML package (Yang, 1997).

\section{RESULTS}

\section{$16 \mathrm{~S}$ rRNA-based phylogenetic tree}

Evolutionary trees, based on 16S rDNA sequences, were constructed by the neighbour-joining, parsimony and maximum-likelihood methods. The phylogenetic trees were based on 1546 unambiguously aligned positions, 161 of which were informative under the parsimony criterion. These trees were rooted by using Plesiomonas shigelloides, which is the most closely related species to the Enterobacteriaceae family (Brenner, 1981). The dendrogram in Fig. 1 shows the phylogeny of Enterobacteriaceae obtained by the distance method.

As expected, 16S rDNA sequences from Proteus mirabilis and Proteus vulgaris were closely clustered, regardless the phylogenetic method used. This monophyletic cluster was found to be grouped with sequences from Providencia alcalifaciens and Morganella morganii, which are also closely phenotypically related to each other (Kauffmann, 1954). Unfortunately, the phylogenetic position of this cluster, rooted by Hafnia alvei, differed according to the phylogenetic method used. It was found to be a sister group of Pectobacterium carotovorum, Escherichia coli, Salmonella enterica, Enterobacter spp., Citrobacter freundii and Klebsiella spp. sequences on the distance tree, but was within one of the Serratia species clusters on the parsimony and maximum-likelihood trees (Fig. 1).

16S rDNA sequences from Pectobacterium carotovorum, Escherichia coli, Salmonella enterica, Enterobacter spp., Citrobacter freundii and Klebsiella spp. formed a monophyletic group regardless of the method used. However, the relationships between sequences from Enterobacter spp., Citrobacter freundii and Klebsiella spp. overlapped and were inconsistent with 


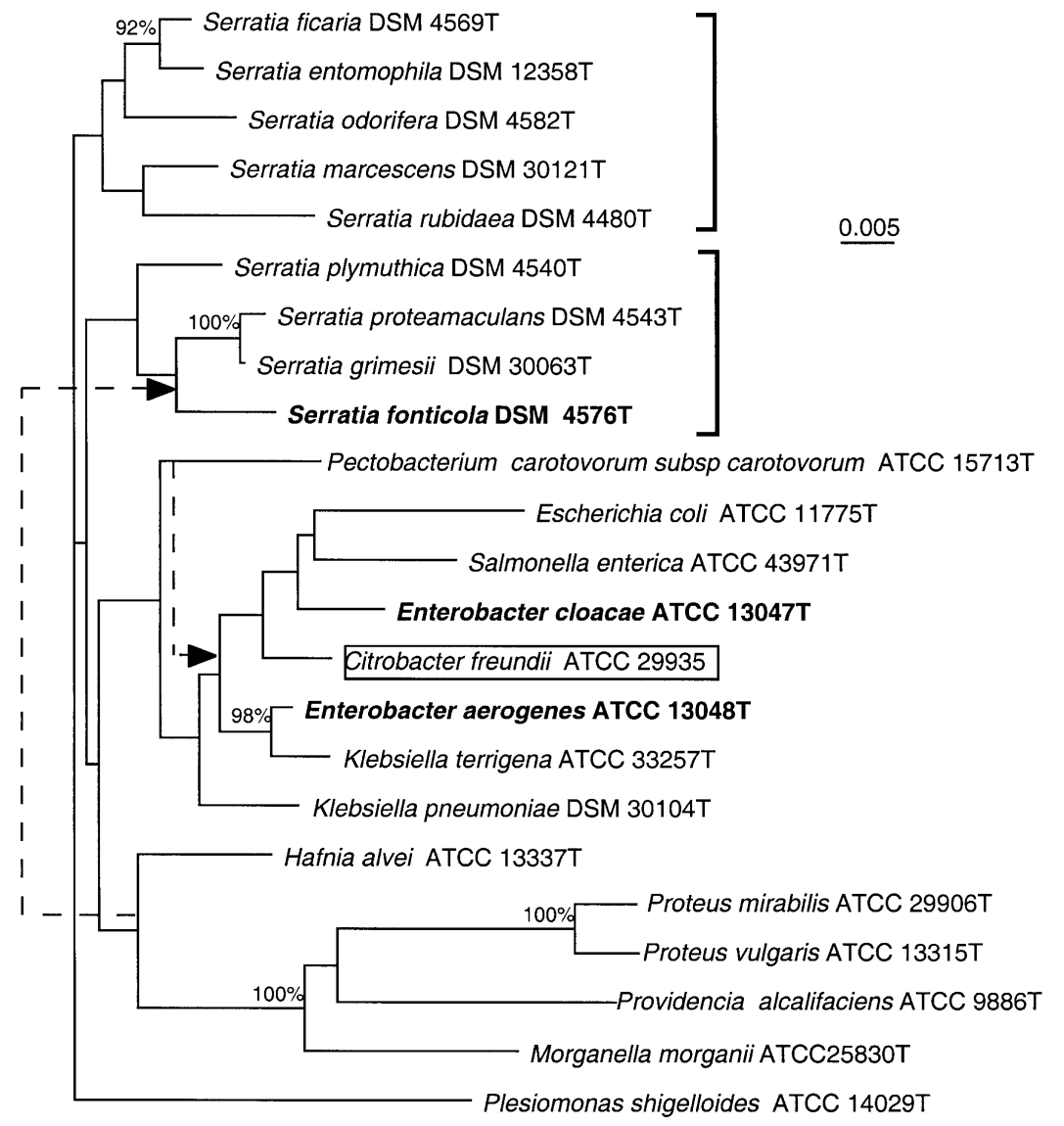

Fig. 1. Neighbour-joining phylogenetic tree obtained from $16 \mathrm{~S}$ rRNA gene sequences. The scale bar represents an estimated 5 base substitutions per $1000 \mathrm{nt}$ positions. Percentages refer to significant bootstrap values of 100 calculated trees. The broken lines with an arrowhead show the position of the Pectobacterium carotovorum branch and the Hafnia alvei-Proteus spp.-Morganella morganii-Providencia alcalifaciens cluster obtained with maximum-parsimony and maximum-likelihood methods. bacterial taxonomy. Enterobacter cloacae was more closely related to Salmonella enterica and Citrobacter freundii, whereas Enterobacter aerogenes grouped with Klebsiella terrigena (Fig. 1).

Two separate clusters (no significant bootstrap values) were obtained for Serratia species, as described by Spröer et al. (1999). One cluster contained Serratia marcescens, Serratia rubidaea, Serratia odorifera, Serratia ficaria and Serratia entomophila. Serratia ficaria and Serratia entomophila formed the deepest branch of the distance tree (Fig. 1). The second cluster, which contained Serratia plymuthica, Serratia grimesii and Serratia proteamaculans, also included Serratia fonticola (Dauga et al., 1990; Spröer et al., 1999) which does not have all the key phenotypic characteristics of the Serratia genus (Gavini et al., 1979).

16S rDNA sequence comparisons did not confirm the current groups of Serratia, Klebsiella and Enterobacter species (Hauben et al., 1998; Spröer et al., 1999). The bootstrap value at the nodes of a few clusters obtained were too low to induce much confidence. 16S rDNA sequences alone could not resolve the phylogenetic relationships between the Enterobacteriaceae species used. The similarity of the nine Serratia species examined was between 93.9 and $99.3 \%$, and for species from different genera of Enterobacteriaceae the similarity was between 88.1 and $98 \cdot 1 \%$. This low rate of variation of $16 \mathrm{~S}$ rDNA explains the poor phylogenetic information obtained from their sequences. Therefore, I studied $\operatorname{gyr} B$ which has a more variable nucleotide sequence.

\section{Nucleotide polymorphism of gyrB}

The nucleotide sequence of a $971 \mathrm{bp}$ segment of the gyr $B$ gene encoding 323 aa was determined for two strains of Serratia ficaria species, two strains of Serratia entomophila, three strains of Serratia marcescens and one strain for each of the other seven species of Serratia. gyrB genes were also sequenced for 13 strains belonging to 13 species from 10 different genera of Enterobacteriaceae and for the Plesiomonas shigelloides type strain. It was found that amino acids 103, 109, 335 and 337 [Escherichia coli amino acid numbering system (X04341/X00870)], corresponding to sequence base positions 1-3, 21-23, 699-701 and 705-707, and amino acids 114-126, corresponding to sequence base positions 36-72, encoding a glycine-rich helix, were conserved. Both of these regions are involved in maintaining contact with ATP (Huang, 1996). As expected, amino acids Arg-136 (base positions 102-105) and Gly-164 (186-188) (Huang, 1996; Wang, 1996), which are the targets of coumarin- and novobiocin-type antibiotics, were found in all of the sequences. I identified 119 polymorphic nucleotide sites (occurring in 20 codons) in the variable regions of Klebsiella sequences, 120 polymorphic nucleotide sites 
(a)

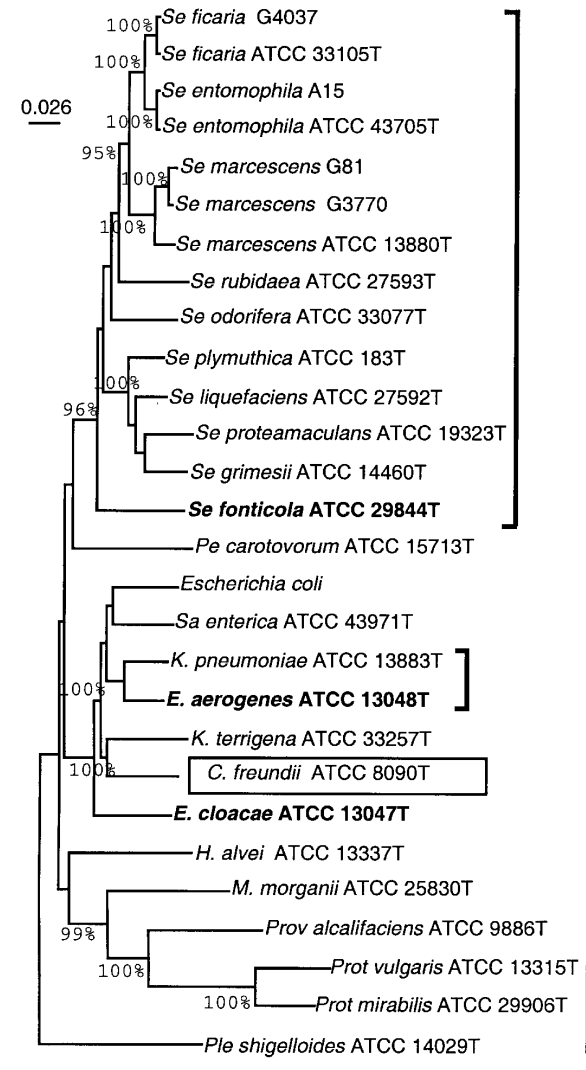

(b)

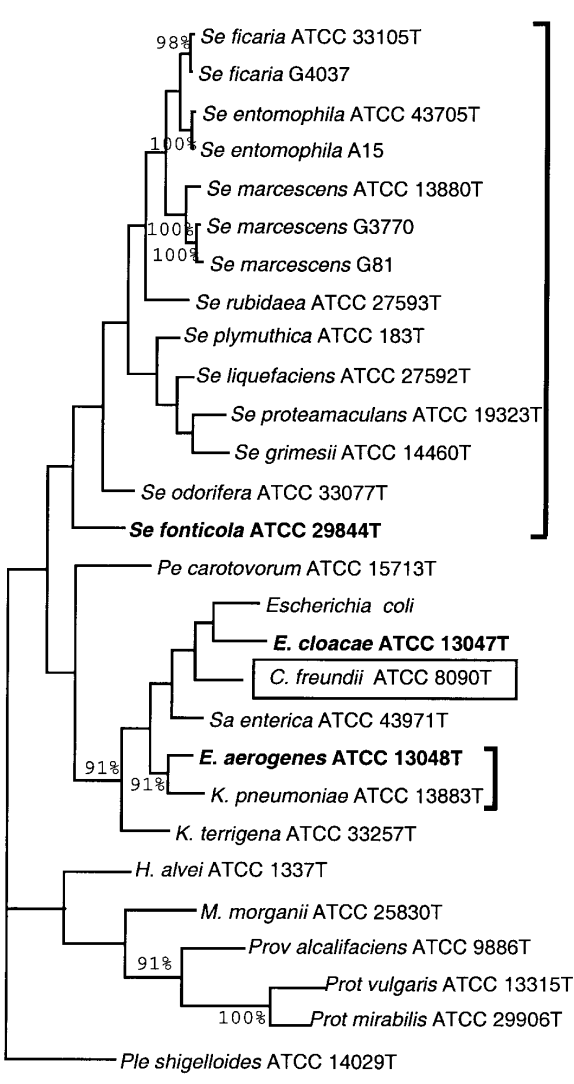

(c)

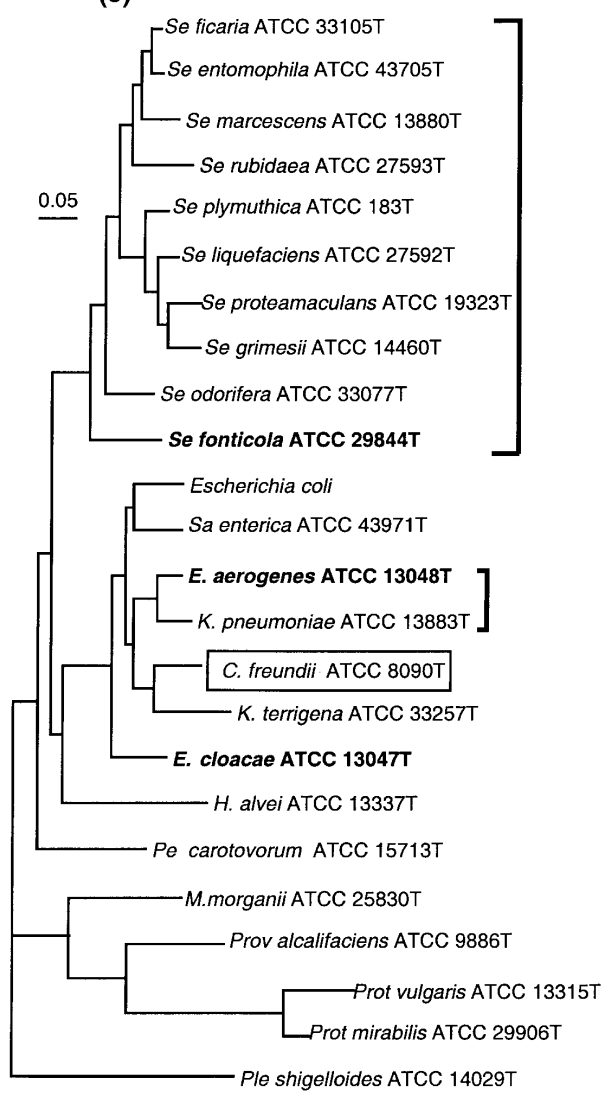

Fig. 2. Phylogenetic trees derived from gyrB sequence comparisons with neighbour-joining (a), parsimony (b) and maximum-likelihood (c) methods. The scale bar represents the number of substitutions per nucleotide position (a and $c$ ). Percentages refer to significant bootstrap values of 100 calculated trees ( $a$ and $b$ ).

(occurring in 18 codons) in Enterobacter sequences, 104 polymorphic nucleotide sites (occurring in 11 codons) in Proteus sequences and 273 polymorphic nucleotide sites (occurring in 48 codons) in the 10 Serratia sequences. One of these sites harboured a Serratia signature sequence. In all Serratia species, gyrB sequences encoded a lysine $(\mathrm{K})$ at codon 206 (base positions 312-314) in a $\beta$-sheet-shaped region of the ATP binding site.

The similarity between nucleotide sequences from three biotypes of Serratia marcescens (Table 1) ranged from 96.5 to $98.9 \%$. Nucleotide sequences from two biotypes of Serratia ficaria and two biotypes of Serratia entomophila showed $99 \cdot 4$ and $99 \cdot 5 \%$ similarities, respectively. These variations were attributable to intraspecies differences. The nucleotide variation of Serratia marcescens strains was greater than that of Serratia ficaria or Serratia entomophila, although the amount of amino acid variation was almost identical in the three species. gyr $B$ nucleotide sequence variability allowed closely related strains to be distinguished within these three Serratia species.

The similarity between $g y r B$ nucleotide sequences from all Serratia species ranged from $84 \cdot 8$ to $97 \cdot 3 \%$. The similarity between their amino acid sequences ranged from 92 to $99 \cdot 4 \%$. Nucleotide sequence similarities within the genera Klebsiella, Enterobacter and Proteus were $87 \cdot 1,87.4$ and $88.9 \%$ respectively, and their amino acid sequence similarities were 93.8, 94.4 and $96.6 \%$, respectively. The amount of variation within Klebsiella, Enterobacter and Proteus were similar to those for Serratia. The gyrB nucleotide sequences contained a mean of three times more mutations than $16 \mathrm{~S}$ rDNA sequences. The high variability of $g y r B$ nucleotide sequences might provide more phylogenetic information than 16S rDNA and enable species relationships within the Enterobacteriaceae to be resolved.

\section{gyrB-based phylogenetic tree}

The phylogenetic trees based on $g y r B$ nucleic acid sequences and obtained with neighbour-joining, parsimony and maximum-likelihood methods are shown in Fig. 2(a), (b) and (c), respectively. They were based on 971 unambiguously aligned positions, corresponding to 381 informative positions under the conditions of parsimony. As before, the trees were rooted by using the Plesiomonas shigelloides sequence. 


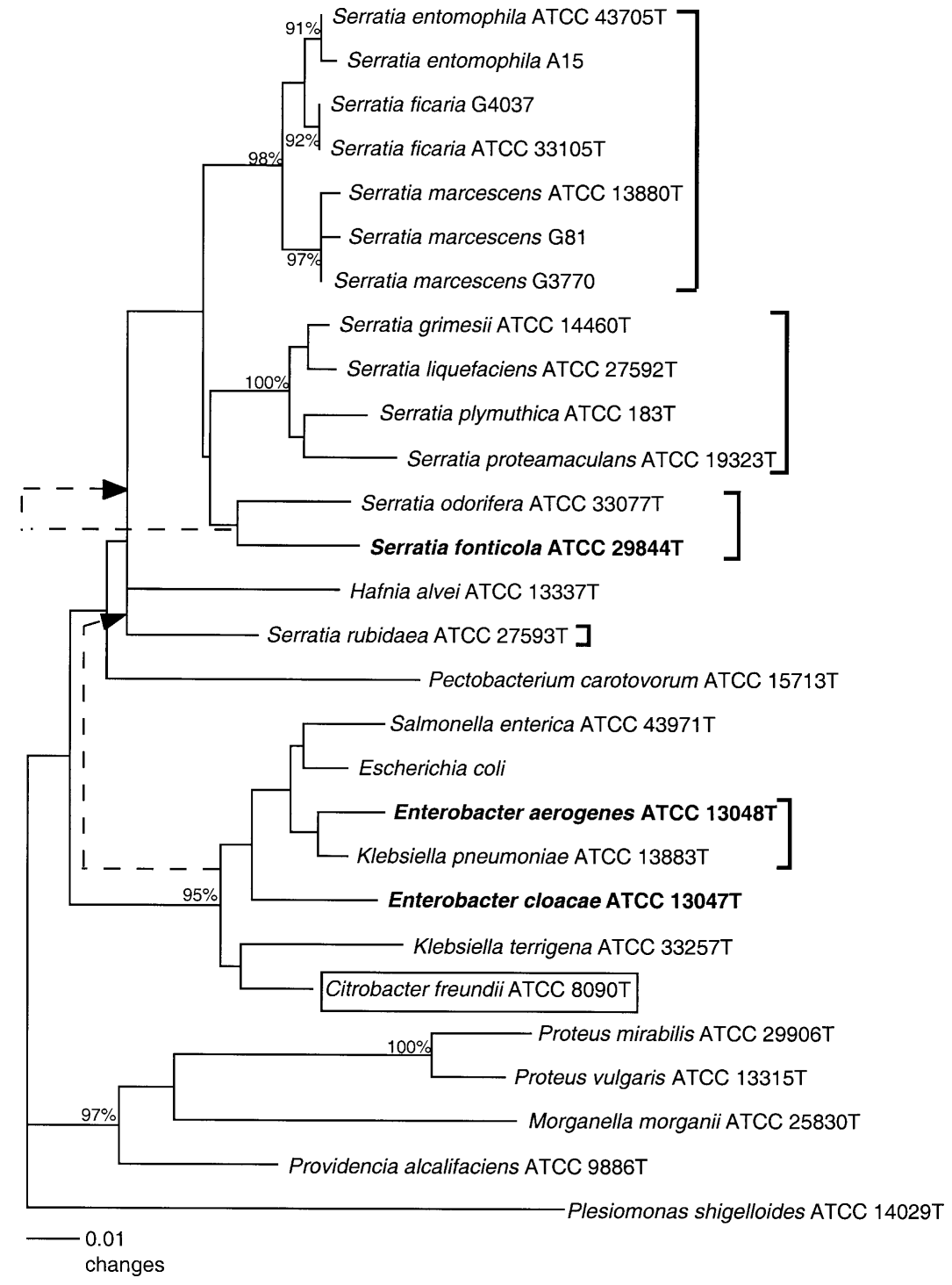

Fig. 3. Neighbour-joining phylogenetic tree obtained from GyrB protein sequences. The scale bar represents the estimated number of amino acid replacements per position. Percentages refer to significant bootstrap values of 100 calculated trees. The broken lines with an arrowhead show the position of the species pair Serratia odorifera and Serratia fonticola and the Salmonella enterica-Citrobacter freundii-Escherichia coli-Enterobacter spp.-Klebsiella spp. cluster obtained with maximum-parsimony method.
Regardless of the phylogenetic methods employed, the Proteus, Providencia and Morganella sequences formed a monophyletic cluster validated with a significant bootstrap value branching out the other enteric species (Fig. 2a, b and c). gyrB sequences from Escherichia, Salmonella, Klebsiella, Enterobacter and Citrobacter species also formed a monophyletic group with a significant bootstrap value (Fig. 2a and b). Serratia gyrB sequences formed one monophyletic group, which was validated by a significant bootstrap value $(96 \%)$ on the distance phylogenetic tree (Fig. $2 \mathrm{a})$, and supported by a bootstrap value of $75 \%$ on the maximum-parsimony phylogenetic tree (Fig. 2b). The phylogenetic positions of Pectobacterium carotovorum and Hafnia alvei remained variable according to the phylogenetic method used (Fig. 2a, b and c).

Two phylogenetic clusters, validated with significant bootstrap values, were found within the Serratia group. The first cluster included Serratia entomophila and Serratia ficaria, from insects, and Serratia marce- scens, a human opportunistic pathogen. The second cluster grouped Serratia grimesii with Serratia liquefaciens, Serratia proteamaculans and Serratia plymuthica, three different species initially included on the basis of phenotypic characteristics in the species Serratia liquefaciens (Grimont et al., 1982a, b). Consistent with its atypical phenotypic characteristics, Serratia fonticola had the most deeply branching gyr $B$ sequence in the Serratia group (Fig. 2a, b and c).

Both Klebsiella and Enterobacter genera remained polyphyletic on the $\operatorname{gyr} B$ phylogenetic tree. $\operatorname{gyr} B$ sequences from Klebsiella pneumoniae and Klebsiella terrigena, which are often confused by commercial identification systems (Monnet \& Freney, 1994), did not place these two species in the same group. Likewise, sequences from Enterobacter cloacae and Enterobacter aerogenes, two important hospital pathogens, were not grouped on the tree. In fact, Enterobacter aerogenes was more closely related to Klebsiella pneumoniae. This relationship is consistent with the small number of 
differences observed between their phenotypic characteristics, which sometimes leads to non-motile strains of Enterobacter aerogenes being confused with Klebsiella pneumoniae (Brenner, 1981). Different phylogenetic positions were obtained for Enterobacter cloacae, depending on the phylogenetic method used. The parsimony and maximum-likelihood (without gamma rate among sites) methods found that Enterobacter cloacae branched near to Escherichia coli (Fig. 2b). However, the distance and maximum-likelihood methods (with gamma rate among sites) found that Enterobacter cloacae lay outside the common ancestor of Escherichia coli, Salmonella enterica, Citrobacter freundii, Klebsiella spp. and Enterobacter aerogenes (Fig. 2a and c). Finally, the distance and maximumlikelihood phylogenetic trees placed Citrobacter freundii near Klebsiella terrigena (Fig. 2a and c), which is in complete disagreement with the phenotypic data.

The phylogenetic relationships of the GyrB protein sequences were also investigated using the neighbourjoining and maximum-parsimony approaches (Fig. 3). The 325 unambiguously aligned amino acids contained only 66 informative positions under the conditions of parsimony.

GyrB sequences formed a monophyletic cluster for Proteus, Providencia and Morganella sequences branching out the other enteric species, as previously described with nucleic acid data (Fig. 2a, b, c and Fig. 3). GyrB sequences from Escherichia, Salmonella, Klebsiella, Enterobacter and Citrobacter species also formed a monophyletic group with a significant bootstrap value (Fig. 3). Citrobacter freundii was closely related to Klebsiella terrigena. Enterobacter aerogenes still grouped with Klebsiella pneumoniae, but without significant bootstrap value.

Serratia GyrB protein sequences did not form a monophyletic group on both distance and maximumparsimony phylogenetic trees (Fig. 3). The neighbourjoining algorithm placed the species pair Hafnia alvei and Serratia rubidaea at the root of the other Serratia spp. The Serratia genus represented a polyphyletic assemblage with the maximum-parsimony method. The poor phylogenetic information contained in GyrB protein sequences, about half the informative position numbers of $16 \mathrm{~S}$ rRNA, explains the uncertainties of the branching patterns for such intrageneric relationships.

The phylogenetic relationships determined by $g y r B$ gene and GyrB protein sequence analyses were more consistent than those established by the 16S rRNA phylogenetic tree for Klebsiella pneumoniae and Enterobacter aerogenes. Because of its high variability, gyrB gene phylogenetic analysis was more reliable than 16S rRNA and GyrB protein analyses to infer intrageneric relationships of Serratia species. However, although the gyr $B$ phylogenetic tree contained 13 strongly supported groups, the use of different phylogenetic methods revealed uncertainties in the branching order of some other Enterobacteriaceae. Therefore,
I tried to determine whether phylogenetic construction bias, such as saturation or long-branch-attracting phenomena, could explain the lack of resolution of gyr $B$ genes for inferring some phylogenetic relationships.

\section{Limitation of gyrB-gene-based phylogeny due to high evolutionary rates}

Due to the high evolutionary rate of the $\operatorname{gyr} B$ gene, multiple substitutions often occur at the same nucleotide position. This implies that there has been mutational saturation of $g y r B$ nucleotide sequences, which is known to confuse phylogenetic inferences (LeblondBourget et al., 1996). This phenomenon was obvious when the Haemophilus influenzae sequence was added. This resulted in the Enterobacteriaceae family cluster being broken (data not shown). Thus, the high levels of gyr $B$ nucleotide sequence variation did not allow me to determine the relationships between distantly related organisms.

I compared inferred substitutions with observed differences in the gyrB sequences of Enterobacteriaceae (data not shown) to determine whether multiple changes that accumulated in the $\operatorname{gyr} B$ sequences resulted in false identities and masked the actual number of evolutionary events (Philippe et al., 1994; Griffiths, 1997; Roe et al., 1997). Saturation analysis clearly indicated that Providencia alcalifaciens, Morganella morganii, Proteus mirabilis and Proteus vulgaris sequences were mutationally saturated.

In addition, these species were too deeply rooted in the gyr B phylogenetic tree attracted by outgroup (Fig. 2a, $\mathrm{b}$ and $\mathrm{c}$ ). This phenomenon is known as long branch attracting (Philippe \& Laurent, 1998) and occurred because the evolutionary rates of this branch were three times greater than in other branches.

Saturation and long branch attracting both meant that the phylogenetic positions obtained with $g y r B$ genes of Providencia alcalifaciens, Morganella morganii, Proteus mirabilis and Proteus vulgaris were uncertain.

\section{Nucleotide composition, codon usage and the genetic transfer hypothesis}

Horizontal gene transfer may explain some of the discrepancies between the defined clusters on phylogenetic gene trees and the groups predicted by phenotypic data. Horizontally transferred genes reflect the genome composition of the donor at the time of introgression, and over time they acquire the DNA composition (biases and asymmetries) of the new genome (Lawrence \& Ochman, 1997). Therefore, the $\mathrm{G}+\mathrm{C}$ content [total gene $\mathrm{G}+\mathrm{C}$ content and third codon position $\mathrm{G}+\mathrm{C}$ content (GCIII)] and the relatedness of codon usage of $g y r B$ genes were studied.

The variations between the total $\mathrm{G}+\mathrm{C}$ contents of the gyr $B$ genes and the mean genomic $\mathrm{G}+\mathrm{C}$ content of the strains used in this study were not significantly large 
Table 2. Comparison between $g y r B, r e c F, d n a N$ and $d n a A$ genes and genome nucleotide compositions

\begin{tabular}{|c|c|c|c|c|c|c|}
\hline & \multicolumn{5}{|c|}{$\mathbf{G}+\mathbf{C}$ nucleotide composition ( $\mathrm{mol} \%$ ) } & \multirow{2}{*}{$\begin{array}{c}\text { Genomic } \mathbf{G}+\mathbf{C} \text { content } \\
(\mathbf{m o l} \%)^{*}\end{array}$} \\
\hline & $\operatorname{gyr} B$ & $\operatorname{gyr} B$ (at 3rd codon) & recF & $\operatorname{dnaN}$ & $\operatorname{dna} A$ & \\
\hline Escherichia coli & $54 \cdot 94$ & $63 \cdot 47$ & $55 \cdot 08$ & $54 \cdot 17$ & $54 \cdot 03$ & $51 \cdot 0$ \\
\hline Citrobacter freundii & $53 \cdot 91$ & $59 \cdot 75$ & & & & $50 \cdot 5$ \\
\hline Salmonella enterica ser. Typhimurium & $55 \cdot 04$ & $63 \cdot 58$ & $54 \cdot 68$ & $56 \cdot 45$ & $52 \cdot 29$ & $51 \cdot 5$ \\
\hline Enterobacter aerogenes & $55 \cdot 56$ & $65 \cdot 94$ & & & & $53 \cdot 5$ \\
\hline Enterobacter cloacae & $54 \cdot 22$ & $65 \cdot 01$ & & & & $53 \cdot 0$ \\
\hline Pectobacterium carotovorum & $53 \cdot 23$ & $59 \cdot 56$ & & & & $51 \cdot 8$ \\
\hline Hafnia alvei & $49 \cdot 38$ & $49 \cdot 22$ & & & & $48 \cdot 3$ \\
\hline Klebsiella pneumoniae & $57 \cdot 10$ & $69 \cdot 65$ & & & & $57 \cdot 0$ \\
\hline Klebsiella terrigena & $55 \cdot 97$ & $67 \cdot 49$ & & & & $56 \cdot 7$ \\
\hline Serratia entomophila & $59 \cdot 05$ & $77 \cdot 10$ & & & & $57 \cdot 8 \dagger$ \\
\hline Serratia ficaria & $59 \cdot 36$ & $78 \cdot 63$ & & & & $59 \cdot 6$ \\
\hline Serratia fonticola & $54 \cdot 32$ & $65 \cdot 63$ & & & & $50 \cdot 6$ \\
\hline Serratia grimesii & $52 \cdot 67$ & $59 \cdot 75$ & & & & $53 \cdot 5 \ddagger$ \\
\hline Serratia liquefaciens & $55 \cdot 25$ & $67 \cdot 49$ & & & & $53 \cdot 5 \ddagger$ \\
\hline Serratia marcescens & $59 \cdot 77$ & $77 \cdot 40$ & & & $58 \cdot 11$ & $58 \cdot 7$ \\
\hline Serratia odorifera & $57 \cdot 51$ & $74 \cdot 60$ & & & & $54 \cdot 6$ \\
\hline Serratia plymuthica & $56 \cdot 07$ & $69 \cdot 04$ & & & & $55 \cdot 0$ \\
\hline Serratia proteamaculans & $52 \cdot 67$ & $61 \cdot 00$ & & & & $53 \cdot 5 \ddagger$ \\
\hline Serratia rubidaea & $60 \cdot 39$ & $78 \cdot 94$ & & & & $55 \cdot 9$ \\
\hline Proteus mirabilis & $41 \cdot 67$ & $29 \cdot 72$ & $41 \cdot 78$ & $43 \cdot 35$ & 41.94 & $39 \cdot 3$ \\
\hline Proteus vulgaris & $40 \cdot 64$ & $29 \cdot 10$ & & & & $39 \cdot 3$ \\
\hline Providencia alcalifaciens & $44 \cdot 65$ & $37 \cdot 77$ & & & & $41 \cdot 5$ \\
\hline Morganella morganii & $53 \cdot 19$ & $60 \cdot 68$ & & & & $50 \cdot 0$ \\
\hline Plesiomonas shigelloides & $54 \cdot 18$ & $61 \cdot 60$ & & & & $51 \cdot 0$ \\
\hline
\end{tabular}

* Genomic G + C content (at the species level) from Krieg \& Holt (1984).

$\dagger$ Genomic G + C content from Serratia entomophila strain ATCC 43705 (Grimont et al., 1988).

$\$$ Mean genomic G + C content of the Serratia liquefaciens species complex (Grimont et al., 1982b).

enough to clearly indicate interspecies gene transfer. The total $\mathrm{G}+\mathrm{C}$ content of the gyr $B$ genes was similar or slightly higher than the genomic $\mathrm{G}+\mathrm{C}$ content for each species (Table 2). As the divergence in the $\mathrm{G}+\mathrm{C}$ content of genes may be related to their chromosomal location (Deschavanne \& Filipski, 1995; Lobry, 1996) the $\mathrm{G}+\mathrm{C}$ contents of $g y r B$ genes were compared with those of genes from the same genome region (when available). The genome data from Escherichia coli, Salmonella enterica, Serratia marcescens and Proteus mirabilis (Burland et al., 1993; Sanderson et al., 1995; Skovgaard \& Hansen, 1987; Skovgaard, 1990) showed that the total $\mathrm{G}+\mathrm{C}$ contents of $g y r B$ genes were approximately equal to those of the neighbouring genes: $r e c F$ (required for recombination and repair), dnaN (encoding the DNA polymerase III $\beta$-subunit) and dnaA (required for initiation of chromosomal replication). No proof of lateral gene transfer was obtained for these species.

The highest GCIII content values correlated with high values of genomic G $+\mathrm{C}$ content for Serratia rubidaea, Serratia marcescens, Serratia ficaria and Serratia entomophila (Table 2). The GCIII content of $g y r B$ sequences was lower than the low overall genomic
$\mathrm{G}+\mathrm{C}$ content of Proteus mirabilis, Proteus vulgaris and Providencia alcalifaciens. The GCIII content was generally higher than the overall genomic $\mathrm{G}+\mathrm{C}$ content in genomes with medium $\mathrm{G}+\mathrm{C}$ content, as described by Muto \& Osawa (1987).

The large differences observed between the total $\mathrm{G}+\mathrm{C}$ content and GCIII content of $\operatorname{gyr} B$ sequences arose because the third codon position has less functional importance (Muto \& Osawa, 1987; Majumdar et al., 1999), except for Hafnia alvei in which GCIII content was equal to the total $\mathrm{G}+\mathrm{C}$ content of $\operatorname{gyr} B$. This atypical GCIII content may have arisen due to the ancient acquisition of a foreign gene.

I also sought a codon usage bias among $\operatorname{gyr} B$ genes to detect gene transfer. Genes in species that are closely phylogenetically related tended to be rather homogeneous in codon usage. Closely related species, such as Escherichia coli and Salmonella enterica, have very similar codon preferences, whereas distant species, such as Bacillus subtilis, have different preferential codon usage patterns (Andersson \& Kurland, 1990). Therefore, I compared codon usages of gyr $B$ genes among Enterobacteriaceae species. 


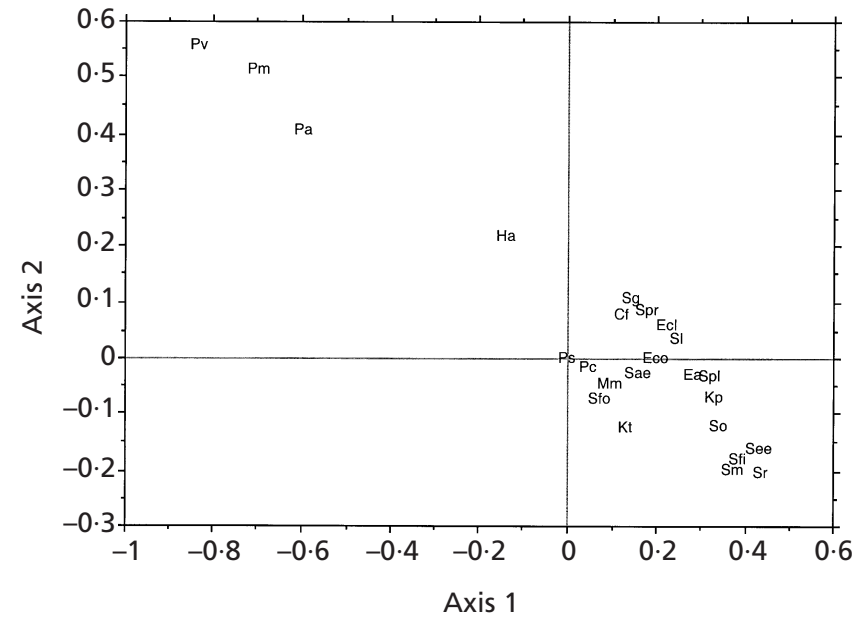

Fig. 4. Correspondence analysis of RSCU in 23 Enterobacteriaceae species. Cf, Citrobacter freundii; Ea, Enterobacter aerogenes; Ecl, Enterobacter cloacae; Eco, Escherichia coli; $\mathrm{Ha}$, Hafnia alvei; Kp, Klebsiella pneumoniae; Kt, Klebsiella terrigena; Mm, Morganella morganii; $\mathrm{Pa}$, Providencia alcalifaciens; Pc, Pectobacterium carotovorum; Pm, Proteus mirabilis; Pv, Proteus vulgaris; See, Serratia entomophila; Sfi, Serratia ficaria; Sfo, Serratia fonticola; Sg, Serratia grimesii; Sl, Serratia liquefaciens; Sm, Serratia marcescens; So, Serratia odorifera; Spl, Serratia plymuthica; Spr, Serratia proteamaculans; Sr, Serratia rubidaea; Sae, Salmonella enterica; Ps, Plesiomonas shigelloides. Genes are plotted at their coordinates on the two axes produced by the analysis.

The analysis was carried out on the RSCU data. Correspondence analysis of the results (Fig. 4) identified the major trends in codon usage: the vertical axis is associated with GCIII (Musto et al., 1998), the horizontal axis is correlated with the frequencies of codons ending in $\mathrm{C}$ or $\mathrm{U}$ versus $\mathrm{A}$ or $\mathrm{G}$ (Fennoy \& Bailey-Serres, 1993). The codon choice of the Escherichia coli gyr $B$ gene corresponds to the optimal codon choice described for highly expressed genes (Ikemura, 1985; Bulmer, 1988). The codon usages of $\operatorname{gyr} B$ genes of Serratia spp., Klebsiella spp., Enterobacter spp., Pectobacterium carotovorum, Citrobacter freundii and Salmonella enterica were almost comparable to that of Escherichia coli on the RSCU correspondence analysis plot (Fig. 4). Analysis of codon usage did not show any bias that might be the result of gene transfer in these species.

The codon usage of Proteus mirabilis, Proteus vulgaris and Providencia alcalifaciens is most characteristic of A + T-biased micro-organisms in which codons with an $\mathrm{A}$ or $\mathrm{T}$ in the third position are used preferentially (Ohtaka \& Ishikawa, 1993).

The differences between Escherichia coli and Hafnia alvei codon usage are principally due to the use of $\mathrm{U}$ instead of $\mathrm{C}$ at the first or the third codon positions for the amino acids Asp, Gly, His, Leu, Pro and Ser. The atypical codon usage of the $g y r B$ gene was confirmed when the codon usages of the genes encoding the RNA polymerase $\beta$-subunit (rpoB, accession number U77438) and translational initiation factor 2 (inf $B$, accession number AJ227978) of the Hafnia alvei genome were checked (data not shown). This extremely atypical codon usage (different from that of Proteus spp.) and the unusual gyr $B$ GCIII content may reflect the acquisition of $g y r B$ by horizontal transfer in Hafnia alvei.

Table 3. Number of substitutions per synonymous site $\left(d_{s}\right)$ and per non-synonymous site $\left(d_{N}\right)$ calculated by the method of Nei \& Gojobori (1986)

Statistical significance between means of $d_{\mathrm{N}}$ or $d_{\mathrm{N}} / d_{\mathrm{S}}$ from nucleotide positions 1-200 and 201-971 were calculated by $t$-tests with $P$ values of $5(*)$ and $1 \%(* *)$. Values that differ between nucleotide positions 1-200 and 201-971 are in bold type.

\begin{tabular}{|c|c|c|c|c|c|c|c|c|c|}
\hline \multirow[t]{2}{*}{ Comparison } & \multicolumn{3}{|c|}{ Domain I (1-200) } & \multicolumn{3}{|c|}{ Domain II (201-971) } & \multicolumn{3}{|c|}{$(1-971)$} \\
\hline & $d_{\mathrm{N}}$ & $d_{\mathrm{s}}$ & $d_{\mathrm{N}} / d_{\mathrm{S}}$ & $d_{\mathrm{N}}$ & $d_{\mathrm{s}}$ & $d_{\mathrm{N}} / d_{\mathrm{S}}$ & $d_{\mathrm{N}}$ & $d_{\mathrm{S}}$ & $d_{\mathrm{N}} / d_{\mathrm{S}}$ \\
\hline \multicolumn{10}{|l|}{ Within: } \\
\hline Serratia genus & 0.045 & 0.562 & $0 \cdot 085$ & 0.027 & 0.473 & $0 \cdot 054$ & $0 \cdot 031$ & $0 \cdot 491$ & $0 \cdot 065$ \\
\hline $\begin{array}{l}\text { Serratia liquefaciens-Serratia plymuthica- } \\
\text { Serratia grimesii-Serratia proteamaculans }\end{array}$ & $0 \cdot 012$ & 0.520 & $0 \cdot 025$ & 0.019 & $0 \cdot 437$ & $0 \cdot 043$ & $0 \cdot 013$ & $0 \cdot 334$ & $0 \cdot 041$ \\
\hline Serratia entomophila-Serratia ficaria-Serratia marcescens & 0.021 & $0 \cdot 318$ & 0.070 & $0.005 *$ & $0 \cdot 204$ & $0.018^{* *}$ & 0.008 & $0 \cdot 231$ & 0.033 \\
\hline Enterobacter genus & 0.085 & 0.564 & $0 \cdot 151$ & 0.024 & 0.628 & 0.039 & 0.036 & $0 \cdot 610$ & 0.059 \\
\hline Klebsiella genus & 0.134 & 0.603 & $0 \cdot 223$ & 0.009 & 0.628 & 0.014 & $0 \cdot 041$ & 0.559 & 0.074 \\
\hline \multicolumn{10}{|l|}{ Between: } \\
\hline Enterobacter aerogenes and Klebsiella pneumoniae & 0.028 & 0.366 & 0.078 & 0.005 & $0 \cdot 313$ & 0.017 & $0 \cdot 010$ & $0 \cdot 322$ & 0.031 \\
\hline Enterobacter cloacae and Escherichia coli & 0.021 & 0.670 & $0 \cdot 032$ & 0.023 & 0.518 & $0 \cdot 045$ & 0.023 & 0.554 & 0.041 \\
\hline Escherichia coli and Salmonella enterica & 0.021 & 0.771 & $0 \cdot 028$ & 0.011 & $0 \cdot 483$ & $0 \cdot 023$ & $0 \cdot 013$ & $0 \cdot 543$ & 0.025 \\
\hline Citrobacter freundii and Escherichia coli & 0.081 & 1.287 & 0.063 & 0.015 & 0.465 & 0.032 & 0.028 & $0 \cdot 591$ & 0.047 \\
\hline Citrobacter freundii and Salmonella enterica & $0 \cdot 105$ & 1.699 & 0.062 & 0.012 & 0.365 & 0.032 & 0.029 & $0 \cdot 515$ & 0.057 \\
\hline Citrobacter freundii and Klebsiella terrigena & 0.058 & 0.643 & 0.090 & 0.023 & $0 \cdot 613$ & 0.037 & 0.029 & $0 \cdot 626$ & 0.047 \\
\hline
\end{tabular}




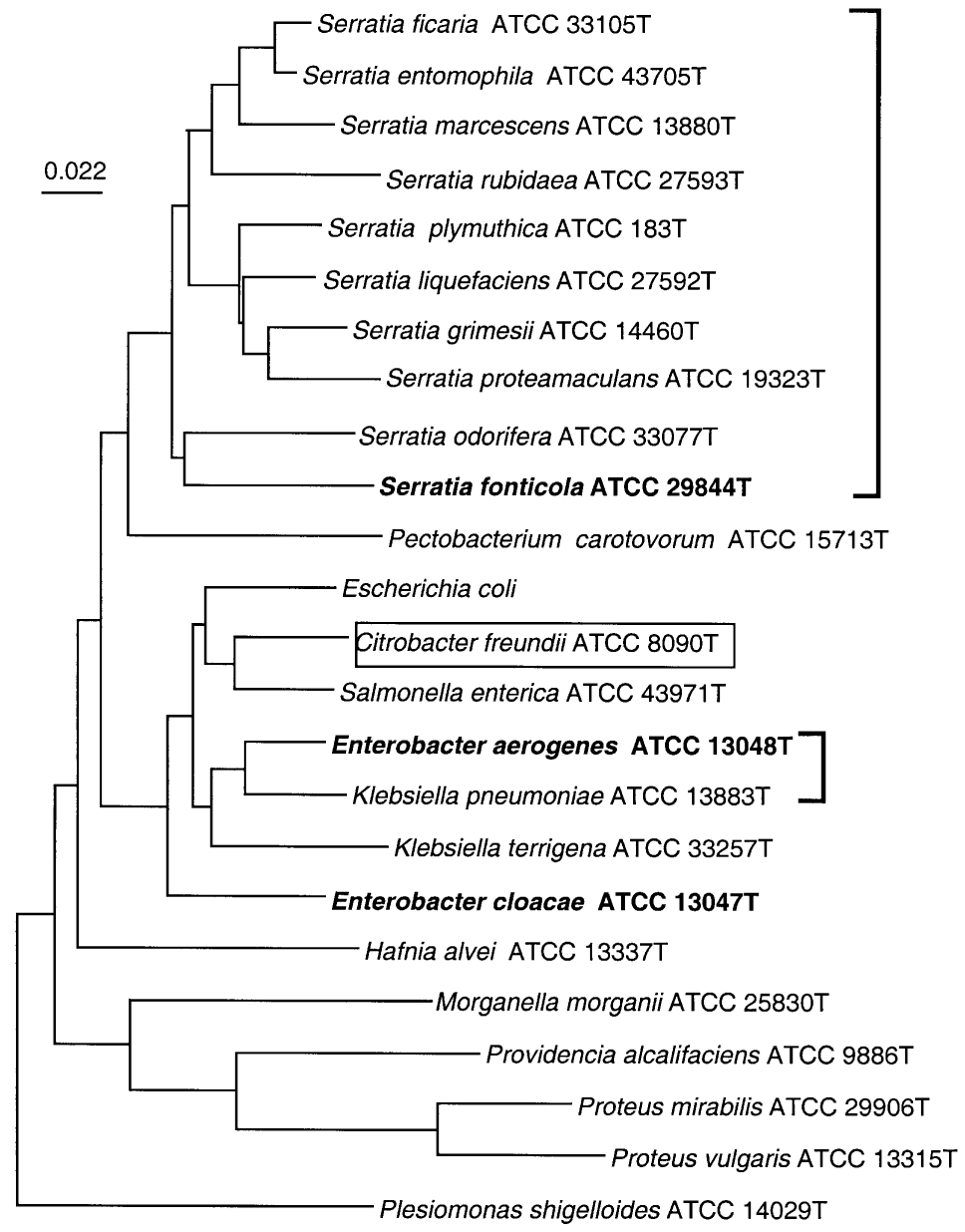

Fig. 5. Neighbour-joining phylogenetic tree based only on the restricted domain II (771 bp) of gyrB sequences. The scale bar represents an estimated 22 base substitutions per $1000 \mathrm{nt}$ positions according to the Kimura index.

\section{Synonymous and non-synonymous substitution analysis}

Mutation rates may vary among sites because of different selective constraints at different sites depending on the functional and/or structural requirements of the gene or protein. Failure to account for rate variation can lead to incorrect construction of phylogenies (Yang, 1996). Therefore, I analysed the number of synonymous substitutions per synonymous site $\left(d_{\mathrm{S}}\right)$ and the number of non-synonymous substitutions per non-synonymous site $\left(d_{\mathrm{N}}\right)$ for the entire nucleotide sequences. Visual analysis of the alignment showed that amino acid substitutions occurred more frequently at the $5^{\prime}$ end of the sequence, thus $d_{\mathrm{S}}$ and $d_{\mathrm{N}}$ were also calculated separately for the first $200 \mathrm{nt}$ (domain I) and for the next $771 \mathrm{nt}$ (domain II) (Table $3)$.

$d_{\mathrm{N}}$ is lower than $d_{\mathrm{S}}$ in all cases (Table 3 ). Therefore, there is clear evidence of selective constraint on amino acid replacements. gyr $B$ has evolved in all the phylogenetic branches under negative or purifying selection.

Analysis of $d_{\mathrm{N}}$ sometimes revealed significant differences between sequence domains from species of the same genus. On average, $d_{\mathrm{N}}$ for sites in domain I was approximately four times greater than for sites in domain II for Serratia entomophila, Serratia ficaria Serratia marcescens and Enterobacter species. $d_{\mathrm{N}}$ was 15 times greater in domain I than in domain II for Klebsiella species. This comparison was the highest found for any pairwise comparison, which suggests that the amount of purifying selection on domain I differs according to the Klebsiella species.

When Citrobacter freundii was compared to Salmonella enterica or Escherichia coli, $d_{\mathrm{S}}$ was approximately four times greater for sites in domain I than for sites in domain II. This surprising result was also obtained with three other Citrobacter sp. sequences (accession numbers AF005699, AF005700 and AF005701) (data not shown). This accelerated rate of substitution had a relatively low impact on $d_{\mathrm{N}}$ in each case and led to seven convergent amino acids, Arg-33, Glu-35, Gly36, Val-38, Glu-40, Thr-42 and Val-44, between GyrB sequences from Citrobacter spp. and Klebsiella terrigena. However, it did appear to create bias for the phylogenetic tree constructions based on both $G y r B$ nucleic acid and GyrB amino acid sequences (Fig. 2 and 3). A phylogenetic tree constructed without sequences from domain I placed Citrobacter freundii in one monophyletic group with Escherichia coli and Salmonella enterica in agreement with phenotypic characters (Fig. 5). Klebsiella terrigena, Klebsiella 
pneumoniae and Enterobacter aerogenes sequences were clustered in another group. Thus, phylogenetic trees may not group Citrobacter freundii, Salmonella enterica and Escherichia coli based on whole gyrB gene sequences due to the unusual evolution of domain I of the Citrobacter freundii gyr $B$ sequence.

The maximum-likelihood model with gamma rate was a good model of tree construction when high variation of substitution among sites occurred (Tateno et al., 1994). In our study, the gamma distribution of amongsite variation rate had a shape parameter alpha of 0.82 , meaning that most sites have low substitution rates, while a few sites have very high substitution rates (Yang, 1996). The position of Enterobacter cloacae was closer to the taxonomy on the maximum-likelihood tree with gamma rate (Fig. 2c) than without gamma rate (data not shown). Unfortunately, this model did not correct the position of Citrobacter freundii (Fig. 2c).

\section{DISCUSSION}

The phylogenetic position of some Enterobacteriaceae and their evolutionary relatedness based upon $16 \mathrm{~S}$ rRNA and $\operatorname{gyr} B$ genes were compared.

Phylogenetic trees based on $\operatorname{gyr} B$ appeared to be more reliable at determining relationships between closely related bacterial species than trees based on $16 \mathrm{~S}$ rDNA sequences. Serratia species formed a monophyletic group or clade based on gyr $B$ sequences. This relationship is supported by high bootstrap values $(96 \%$ for the distance $g y r B$ phylogenetic tree and $75 \%$ for the maximum-parsimony gyrB phylogenetic tree). Thus I consider that a monophyletic relationship between Serratia species is very likely. This shows that phenotypic characteristics were a judicious choice of shared derived characters for defining the members of this genus. Evolutionary relationships between Serratia species were consistent with DNA relatedness clusters (Grimont et al., 1982b). The more distant position of Serratia fonticola in the gyrB phylogenetic tree matches the very low DNA-DNA hybridization values obtained between this species and the other Serratia species. In addition, the gyr $B$ phylogenetic tree highlighted clades of Serratia with different pathogenic behaviour. Serratia entomophila, which is a pathogen of insects (Grimont et al., 1988), Serratia ficaria, an occasional pathogen in humans (Anahory et al., 1998), and Serratia marcescens, which causes nosocomial infections (Hejazi \& Falkiner, 1997), formed a cluster. $S$ rubidaea, an opportunistic pathogen (Ursua et al., 1996), rooted this cluster (Fig. 2a, b and c). Of the environmental species (Serratia grimesii, Serratia plymuthica, Serratia liquefaciens and Serratia proteamaculans) only Serratia liquefaciens is an opportunistic pathogen, involved in hospital-acquired infections, especially in frail patients in which immune function is reduced. Serratia liquefaciens has also been identified as a cause of certain skin lesions (Nitzan et al., 1999). Serratia rubidaea, Serratia marcescens,
Serratia entomophila and Serratia ficaria might share virulence factors that could be inherited from their common ancestor, whereas if Serratia liquefaciens contains these virulence factors it did so by lateral gene transfer.

Phylogenetic trees based on gyrB gene sequences suggested that Klebsiella and Enterobacter species belonged to multiple phylogenetic groups. This confirms previous studies based on genes encoding translation initiation factor 2 (inf B; Hedegaard et al., 1999), the RNA polymerase $\beta$-subunit (rpoB; Mollet et al., 1997), stress protein (groE; Harada \& Ishikawa, 1997) and 16S rRNA (Hauben et al., 1998). Thus, Enterobacter and Klebsiella genera are validly described taxa, which harbour a collection of phylogenetically diverse species. Biochemical and metabolic characteristics might be unable to describe reliable hierarchical grouping of these genera in a cladistic manner. Indeed, phenotypes have a multifactorial genetic basis and their phenotypes could evolve convergently and confuse phenotypic cluster analysis (Lawrence et al., 1991). However, to confirm the trend observed with the phylogenetic analysis of $\operatorname{gyr} B$ genes, many more Enterobacter and Klebsiella species must be included.

In this study, the $g y r B$ - and 16S-rDNA-based trees are not highly congruent for branching patterns of Enterobacter spp. and Klebsiella spp. gyrB and 16S rDNA sequences from Enterobacter aerogenes, Klebsiella terrigena and Klebsiella pneumoniae predicted different highly robust clusters for each molecular-based tree. The 16S rDNA phylogenetic tree grouped Enterobacter aerogenes with Klebsiella terrigena, even though they have different phenotypic characteristics (Izard et al., 1981). This unexpected clustering may be due to rRNA lateral gene transfer, but horizontal transfer was infrequent due to stringent functional constraints (Yap et al., 1999). 16S rDNA sequences are more likely to contain confused molecular synapomorphies and homoplasies, leading to incorrect phylogenetic constructions and high bootstrap values (Lecointre et al., 1993). Molecular phylogeny based on gyrB gene and protein sequences proposed that Enterobacter aerogenes clustered with Klebsiella pneumoniae, which is consistent with the phylogenetic tree based on groE gene sequences (Harada \& Ishikawa, 1997). This is also consistent with the DNA hybridization data and proposals to transfer Enterobacter aerogenes to the Klebsiella genus (Brenner, 1984). The gyrB gene and GyrB protein phylogenetic analyses appeared to be better at determining relationships in this case than $16 \mathrm{~S}$ rDNA.

The DNA-DNA hybridization method, which is the reference method for grouping conspecific bacterial strains (Wayne et al., 1987), has been used to determine the relationships between genera in the Enterobacteriaceae family (Brenner, 1984). However, noise, such as rate variation (with homoplasy), label compression and random experimental error can compromise the distance properties of DNA hybridization values 
(Lapointe \& Kirsch, 1995). This results in unreliable evolutionary relationships of distant taxa being made. Therefore, phylogenetic relationships based on $\operatorname{gyr} B$ or 16S rDNA sequences may be an attractive alternative. Unfortunately, gyrB gene phylogenetic trees sometimes showed conflicting evolutionary relationships between Enterobacteriaceae that disagreed with taxonomy. This was due to inaccuracies of the gyr $B$ trees (phylogenetic construction bias) because of the occurrence of lateral gene transfer and unusual evolutionary processes.

Trees based on gyrB show that Proteus spp., Morganella morganii and Providencia alcalifaciens formed a coherent clade which rooted other Enterobacteriaceae. However, sequence divergences between these species and the other Enterobacteriaceae were saturated; this was partly due to the increased overall level of divergence and also because Proteus spp. and Providencia alcalifaciens are A+T-rich. As shown for the rec $A$ gene (Lloyd \& Sharp, 1993), there is a clearly different preferred codon usage for $\operatorname{gyr} B$ in these species. Thus, phylogenetic groupings based on nucleotide sequences may be directly affected by compositional bias of the genome, irrespective of the evolutionary history of the organisms (Hasegawa \& Hashimoto, 1993). In addition, the high rate of sequence change for Proteus spp., Morganella morganii and Providencia alcalifaciens may create long branch attraction. Indeed, this combination of unusual evolutionary patterns and the low number of species samples used may have led to a biased placement (Graybeal, 1998). The maximum-likelihood with gamma rate method, a phylogenetic method which can correct both of these artifacts (Galtier \& Gouy, 1995; Van de Peer \& De Wachter, 1996), did not modify the phylogenetic position of this group. Although the phylogenetic position of the Proteus spp., Morganella morganii and Providencia alcalifaciens group was identical in the phylogenetic trees based on $\operatorname{gyr} B, 16 \mathrm{~S}$ rRNA (Fig. 1), RNA polymerase $\beta$-subunit (rpoB) and translation initiation factor 2 (inf $B$ ) sequences (Mollet et al., 1997; Hedegaard et al., 1999), the phylogenetic position of $g y r B$ sequences for this group should be interpreted with caution, because of the possibility of artifactual phylogenetic constructions.

To resolve problems due to the high evolutionary rates of nucleic acid data, phylogenetic analysis based on protein-encoding genes can be performed by using the amino acid sequences. Indeed, GyrB protein sequences showed no saturation of phylogenetic information within the Enterobacteriaceae family (data not shown), but their low contents in informative positions did not allow reliable study of phylogenetic relationships within the Serratia genus and between Enterobacter and Klebsiella species.

Discrepancies between the position of Enterobacter cloacae and Citrobacter freundii in gyrB- and 16SrDNA-based phylogenetic trees suggest $\operatorname{gyr} B$ gene lateral transfer. However, codon usage bias and differences between the $\mathrm{G}+\mathrm{C}$ content of the gene and the entire genome did not detect any genes acquired from closely related bacteria with similar base composition or codon usage. Slight variations of codon usage and $\mathrm{G}+\mathrm{C}$ contents of gyrB genes in Escherichia coli, Salmonella enterica, Citrobacter freundii, Pectobacterium carotovorum, Enterobacter spp., Klebsiella spp. and Serratia spp. were not significant enough to confirm lateral gene transfer between these species.

Slight variations in the $\mathrm{G}+\mathrm{C}$ content of $g y r B$ genes were probably not due to different gene locations in relation to the origin of replication (Jensen et al., 1999; Karlin et al., 1998). Similarly, slight variations in codon usage in $g y r B$ genes were not the result of different gene orientations on the bacterial chromosome due to strand compositional asymmetry (McLean et al., 1998). The chromosome maps and recent genomic data from Escherichia coli, Salmonella enterica, Klebsiella pneumoniae and Proteus mirabilis (Skovgaard, 1990), as well as Yersinia pestis (http:// genome.wustl.edu/gsc/Projects/bacterial/egadsinfo. shtml), Pseudomonas putida (Fujita et al., 1989), Haemophilus influenzae (Fleischmann et al., 1995) and Bacillus subtilis (Fujita et al., 1989), show that the genome region around $g y r B$ is highly conserved. $g y r B$ is located in a chromosomal region that has a central role in the initiation of chromosomal replication. This region is conserved in many Eubacteria and was probably inherited from the ancestral bacterium (Fujita et al., 1989). Therefore, the gyrB gene is probably rarely transferred and is thus a good tool for determining the history of Eubacteria.

The phylogenetic position of Hafnia alvei in the 16SrRNA-based tree (Fig. 1) and the gyr $B$-based tree (Fig. 2a, b, c and Fig. 5) seemed almost congruent. However, the low number of informative positions of sequences for both molecules led to different tree topologies according to the phylogenetic tree methods used. No evidence for lateral gene transfer of 16S rRNA gene segments was obtained because of the lack of a large number of non-random base variations in the alignment of the stable region of the gene (data not shown) (Wang \& Zhang, 2000). On the other hand, the obvious atypical codon usage and unusual GCIII contents in Hafnia alvei suggested that foreign $\operatorname{gyr} B$ gene transfer had occurred in this species. In this case, the phylogenetic position of Hafnia alvei could not be determined, because gyrB trees accurately reflect the evolutionary history of the gene, but not the history of the species (Lawrence, 1999).

The branching of Citrobacter freundii on the gyrB phylogenetic tree was related to the number of synonymous substitutions, reflecting the rate of neutral substitutions (Lenski et al., 1989), observed in different domains of the molecule. Citrobacter freundii, which had significantly different numbers of synonymous substitutions between domains compared to Escherichia coli and Salmonella enterica, branched in the vicinity of Klebsiella terrigena. The phylogenetic method of maximum-likelihood with gamma rate could not correct this, probably because it was too 
widespread. Natural events, such as accelerated rate of substitutions or different levels of selection in a certain domain of the gene, can lead to non-random convergence of the data (Otsuka et al., 1997). Molecular phylogenies based on comparisons of a single gene may be misleading if constraints or specific selections differed between the organisms being considered. Thus, data from several genes encoding different cellular functions should be combined to build the species phylogenetic tree.

Most of the differences between the $\operatorname{gyr} B$ and $16 \mathrm{~S}$ rDNA trees are in areas of low resolution (differences generated by the different methods) or low bootstrap values for one or both of the molecules. The low resolution of the deep branches in the gyr $B$ trees may have been due to poor representation of certain taxa, such as Pectobacterium carotovorum. Future studies will include more species to enable me to assess the overall phylogenetic relationships of Enterobacteriaceae. The number of sequences available at the ICB database (http:/ / www.mbio.co.jp) is growing rapidly. Therefore, gyr $B$ genes could prove useful for evolutionary systematic studies.

Differences in the resolution and the significance of particular branches helped me to define which molecules were useful for specific levels of phylogenetic comparisons: 16S rRNA phylogenetic studies, the reference method for defining phylogenetic lineages (Olsen \& Woese, 1993), described relationships between distantly related Enterobacteriaceae, whereas the $\operatorname{gyr} B$ sequence was more appropriate for inferring intra- and some intergeneric relationships. In the future, $16 \mathrm{~S}$ rDNA combined with the gyrB sequence method may be able to clarify molecular relationships of endosymbiotic Enterobacteriaceae (Heddi et al., 1998; Chen et al., 1999; Sameshima et al., 1999) and to identify viable but non-culturable Enterobacteriaceae in the environment (Vuddhakul et al., 2000).

\section{ACKNOWLEDGEMENTS}

Thanks are due to $\mathrm{C}$. Bizet for providing type strains. Thanks are due to P. A. D. Grimont for providing biotypes of Serratia marcescens, Serratia ficaria and Serratia entomophila. Thanks are also due to S. Yamamoto and P. Bouvet for helpful discussions.

\section{REFERENCES}

Adachi, T., Mizuuchi, M., Robinson, E. A., Appella, E., O'Dea, M. H., Gellert, M. \& Mizuuchi, K. (1987). DNA sequence of the E. coli gyr $B$ gene: application of a new sequencing strategy. Nucleic Acids Res 15, 771-784.

Amann, R. I., Ludwig, W. \& Schleifer, K. H. (1995). Phylogenetic identification and in situ detection of individual microbial cells without cultivation. Microbiol Rev 59, 143-169.

Anahory, T., Darbas, H., Ongaro, O., Jean-Pierre, H. \& Mion, P. (1998). Serratia ficaria: a misidentified or unidentified rare cause of human infections in fig tree culture zones. J Clin Microbiol 36, 3266-3272.

Andersson, S. G. E. \& Kurland, C. G. (1990). Codon preferences in free-living microorganisms. Microbiol Rev 54, 198-210.
Bairoch, A., Bucher, P. \& Hofman, K. (1997). The PRosite database, its status in 1997. Nucleic Acids Res 25, 217-221.

Brenner, D. J. (1981). Introduction to the family Enterobacteriaceae. In The Prokaryotes: a Handbook on the Biology of Bacteria: Ecophysiology, Isolation, Identification, Applications, vol. 3, pp. 2673-2695. Edited by A. Balows, H. G. Trüper, M. Dworkin, W. Harder \& K. H. Schleifer. Berlin: Springer.

Brenner, D. J. (1984). Enterobacteriaceae. In Bergey's Manual of Systematic Bacteriology, vol. 1, pp. 408-420. Edited by N. R. Krieg \& J. G. Holt. Baltimore: Williams \& Wilkins.

Bulmer, M. (1988). Are codon usage patterns in unicellular organisms determined by selection-mutation balance? J Evol Biol 1, 15-26.

Burland, V., Plunkett, G., III, Daniels, D. L. \& Blattner, F. R. (1993). DNA sequence and analysis of 136 kilobases of the Escherichia coli genome: organizational symmetry around the origin of replication. Genomics 16, 551-561.

Chen, X., Li, S. \& Aksoy, S. (1999). Concordant evolution of a symbiont with its host insect species: molecular phylogeny of genus Glossina and its bacteriome-associated endosymbiont, Wigglesworthia glossinidia. J Mol Evol 48, 49-58.

Cho, J. C. \& Kim, S. J. (1999). Green fluorescent protein-based direct viable count to verify a viable but non-culturable state of Salmonella typhi in environmental samples. J Microbiol Methods 36, 227-235.

Christensen, H., Nordentoft, S. \& Olsen, J. E. (1998). Phylogenetic relationships of Salmonella based on rRNA sequences. Int J Syst Bacteriol 48, 605-610.

Cilia, V., Lafay, B. \& Christen, R. (1996). Sequence heterogeneities among $16 \mathrm{~S}$ ribosomal RNA sequences, and their effect on phylogenetic analyses at the species level. Mol Biol Evol 13, 451-461.

Dauga, C., Grimont, F. \& Grimont, P. A. D. (1990). Nucleotide sequences of 16S rRNA from ten Serratia species. Res Microbiol 141, 1139-1149.

Dauga, C., Zabrovskaia, A. \& Grimont, P. A. D. (1998). Restriction fragment length polymorphism analysis of flagellin genes of Salmonella enterica. J Clin Microbiol 36, 2835-2843.

Debabov, V. G. (1999). Bacterial life outside laboratories. Mol Biol 33, 950-958.

Deschavanne, P. \& Filipski, J. (1995). Correlation of GC content with replication timing and repair mechanisms in weakly expressed E. coli genes. Nucleic Acids Res 23, 1350-1353.

Dore, J., Gramet, G., Goderel, I. \& Pochart, P. (1998). Cultureindependent characterization of human faecal flora using rRNAtargeted hybridisation probes. Genet Sel Evol 30, S287-S296.

Farmer, J. J., III, Davis, B. R., Hickman-Brenner, F. W. \& 12 other authors (1985). Biochemical identification of new species and biogroups of Enterobacteriaceae isolated from clinical specimens. J Clin Microbiol 21, 46-76.

Felsenstein, J. (1981). Evolutionary trees from DNA sequences: a maximum likelihood approach. $J$ Mol Evol 17, 368-376.

Felsenstein, J. (1985). Confidence limits on phylogenies: an approach using the bootstrap. Evolution 39, 783-791.

Felsenstein, J. (1993). Phylogenies inference package (PHYLIP), version 3.53c. Seattle: Department of Genetics, University of Washington.

Fennoy, S. L. \& Bailey-Serres, J. (1993). Synonymous codon usage in Zea mays L. nuclear genes is varied by levels of C and G-ending codons. Nucleic Acids Res 21, 5294-5300.

Fleischmann, R. D., Adams, M. D., White, O. \& 37 other authors (1995). Whole-genome random sequencing and assembly of Haemophilus influenzae Rd. Science 269, 496-512.

Fox, G. E., Stackebrandt, E., Hespell, R. B. \& 16 other authors (1980). The phylogeny of prokaryotes. Science 209, 457-463.

Fujita, M. Q., Yoshijawa, H. \& Ogasawara, N. (1989). Structure of the dnaA region of Pseudomonas putida: Conservation among three bacteria, Bacillus subtilis, Escherichia coli and P. putida. Mol Gen Genet 215, 381-387. 
Galtier, N. \& Gouy, M. (1995). Inferring phylogenies from DNA sequences of unequal base compositions. Proc Natl Acad Sci U S A 92 , $11317-11321$

Gavini, F., Ferragut, C., Izard, D., Trinel, P. A., Leclerc, H., Lefebvre, B. \& Mossel, D. A. A. (1979). Serratia fonticola, a new species from water. Int $J$ Syst Bacteriol 29, 92-101.

Gherna, R. L., Werren, J. H., Weisburg, W., Cote, R., Woese, C. R., Mandelco, L. \& Brenner, D. J. (1991). Arsenophonus nasionae gen. nov., sp. nov., the causative agent of the Son-Killer trait in the parasitic wasp Nasonia vitripennis. Int J Syst Bacteriol 41, 563-565.

Grantham, R., Gautier, C., Gouy, M., Jacobzone, M. \& Mercier, R. (1981). Codon catalog usage is a genome strategy modulated for gene expressivity. Nucleic Acids Res 9, r43-r74.

Graybeal, A. (1998). Is it better to add taxa or characters to a difficult phylogenetic problem? Syst Biol 47, 9-17.

Griffiths, C. S. (1997). Correlation of functional domains and rates of nucleotide substitution in cytochrome b. Mol Phylogenet Evol 7 , 352-365.

Grimont, P. A. D., Grimont, F. \& Irino, K. (1982a). Biochemical characterization of Serratia liquefaciens sensu stricto, Serratia proteamaculans, and Serratia grimesii sp. nov. Curr Microbiol 7, 69-74.

Grimont, P. A. D., Irino, K. \& Grimont, F. (1982b). The Serratia liquefaciens-S. proteamaculans-S. grimesii complex: DNA relatedness. Curr Microbiol 7, 63-68.

Grimont, P. A. D., Jackson, T. A., Ageron, E. \& Noonan, M. J. (1988). Serratia entomophila sp. nov. associated with amber disease in the New Zealand grass grub Costelytra zealandica. Int J Syst Bacteriol 38, $1-6$.

Harada, H. \& Ishikawa, H. (1997). Phylogenetical relationship based on groE genes among phenotypically related Enterobacter, Pantoea, Klebsiella, Serratia and Erwinia species. J Gen Appl Microbiol 43, 355-361.

Harada, H., Oyaizu, H. \& Ishikawa, H. (1996). A consideration about the origin of aphid intracellular symbiont in connection with gut bacterial flora. J Gen Appl Microbiol 42, 17-26.

Hasegawa, M. \& Hashimoto, T. (1993). Ribosomal RNA trees misleading? Nature 361, 23.

Hauben, H., Moore, E. R. B., Vauterin, L., Steenackers, M., Mergaert, J., Verdonck, L. \& Swings, J. (1998). Phylogenetic position of phytopathogens within Enterobacteriaceae. Syst Appl Microbiol 21, 384-397.

Heddi, A., Charles, H., Khatchadourian, C., Bonnot, G. \& Nardon, P. (1998). Molecular characterization of the principal symbiotic bacteria of the weevil Sitophilus oryzae: a peculiar $\mathrm{G}+\mathrm{C}$ content of an endocytobiotic DNA. J Mol Evol 47, 52-61.

Hedegaard, J., Steffensen, S. A., Norskov-Lauritsen, N., Mortensen, K. K. \& Sperling-Petersen, H. U. (1999). Identification of Enterobacteriaceae by partial sequencing of the gene encoding translation initiation factor 2. Int J Syst Bacteriol 49, 1531-1538.

Hejazi, A. \& Falkiner, F. R. (1997). Serratia marcescens. J Med Microbiol 46, 903-912.

Hickman-Brenner, F. W., Huntley-Carter, G. P., Richard-Fanning, G., Brenner, D. J. \& Farmer, J. J., III. (1985). Koserella trabulsii, a new genus and species of Enterobacteriaceae formerly known as Enteric group 45. J Clin Microbiol 21, 39-42.

Higgins, D. G. (1994). CLUSTAL v: multiple alignment of DNA and protein sequences. In Methods in Molecular Biology. Computer Analysis of Sequence Data Part II, vol. 25, pp. 307-318. Edited by A. M. Griffin \& H. G. Griffin. Totowa, NJ: Humana.

Huang, W. M. (1996). Bacterial diversity based on type II DNA topoisomerase genes. Annu Rev Genet 30, 79-107.

Ibrahim, A., Goebel, B. M., Liesack, W., Griffiths, M. \& Stackebrandt, E. (1993). The phylogeny of the genus Yersinia based on 16S rDNA sequences. FEMS Microbiol Lett 114, 173-178.

Ikemura, T. (1985). Codon usage and tRNA content in unicellular and multicellular organisms. Mol Biol Evol 2, 13-34.

Izard, D., Ferragut, C., Gavini, F., Kersters, K., De Ley, J. \& Leclerc,
H. (1981). Klebsiella terrigena, a new species from soil and water. Int $J$ Syst Bacteriol 31, 116-127.

Jensen, L. J., Friis, C. \& Ussery, D. W. (1999). Three views of microbial genomes. Res Microbiol 150, 773-777.

Karlin, S., Campbell, A. M. \& Mràzek, J. (1998). Comparative DNA analysis across diverse genomes. Annu Rev Genet 32, 185-225.

Kasai, H., Ezaki, T. \& Harayama, S. (2000). Differentiation of phylogenetically related slowly growing Mycobacteria by their gyrB sequences. J Clin Microbiol 38, 301-308.

Kato, J. I., Nishimura, Y., Imamura, R., Niki, H., Hiraga, S. \& Suzuki, H. (1990). New topoisomerase essential for chromosome segregation in E. coli. Cell 63, 393-404.

Kauffmann, F. (1954). Enterobacteriaceae, 2nd edn. Copenhagen: Munksgaard.

Kimura, M. (1980). A simple method for estimating evolutionary rates of base substitutions through comparative studies of nucleotide sequences. J Mol Evol 16, 111-120.

Krieg, N. R. \& Holt, J. G. (editors) (1984). Bergey's Manual of Systematic Bacteriology, vol. 1. Baltimore: Williams \& Wilkins.

Lapointe, F.-J. \& Kirsch, J. A. W. (1995). Estimating phylogenies from lacunose distance matrices, with special reference to DNA hybridization data. Mol Biol Evol 12, 266-284.

Lawrence, J. G. (1999). Gene transfer, speciation, and the evolution of bacterial genomes. Curr Opin Microbiol 2, 519-523.

Lawrence, J. G. \& Ochman, H. (1997). Amelioration of bacterial genomes: rates of change and exchange. $J \mathrm{Mol} \mathrm{Evol} \mathrm{44,} \mathrm{383-397.}$

Lawrence, J. G., Ochman, H. \& Hartl, D. L. (1991). Molecular and evolutionary relationships among enteric bacteria. J Gen Microbiol 137, 1911-1921.

Leblond-Bourget, N., Philippe, H., Mangin, I. \& Decaris, B. (1996). $16 \mathrm{~S}$ rRNA and $16 \mathrm{~S}$ to $23 \mathrm{~S}$ internal transcribed spacer sequence analyses reveal inter- and intraspecific Bifidobacterium phylogeny. Int J Syst Bacteriol 46, 102-111.

Lecointre, G., Philippe, H., Lê, H. L. V. \& Le Guyader, H. (1993). Species sampling has a major impact on phylogenetic inference. $\mathrm{Mol}$ Phylogenet Evol 2, 205-224.

Lenski, R. E., Slatkin, M. \& Ayala, F. J. (1989). Mutation and selection in bacterial populations: alternatives to the hypothesis of directed mutation. Proc Natl Acad Sci U S A 86, 2775-2778.

Liu, J., Berry, R., Poinar, G. \& Moldenke, A. (1997). Phylogeny of Photorhabdus and Xenorhabdus species and strains as determined by comparison of partial 16S rRNA gene sequences. Int J Syst Bacteriol 47, 948-951.

Lloyd, A. T. \& Sharp, P. M. (1993). Evolution of the $r e c A$ gene and the molecular phylogeny of bacteria. J Mol Evol 37, 399-407.

Lobry, J. R. (1996). Asymmetric substitution patterns in the two DNA strands of bacteria. Mol Biol Evol 13, 660-665.

Ludwig, W., Rossello-Mora, R., Aznar, R. \& 14 other authors (1995). Comparative sequence analysis of $23 \mathrm{~S}$ rRNA from proteobacteria. Syst Appl Microbiol 18, 164-188.

Ludwig, W., Strunk, O., Klugbauer, S., Klugbauer, N., Weizenegger, M., Neumaier, J., Bachleitner, M. \& Schleifer, K. H. (1998). Bacterial phylogeny based on comparative sequence analysis. Electrophoresis 19, 554-568.

Majumdar, S., Gupta, S. K., Sundararajan, V. S. \& Ghosh, T. C. (1999). Compositional correlation studies among three different codon positions in 12 bacterial genomes. Biochem Biophys Res Commun 266, 66-71.

McLean, M. J., Wolfe, K. H. \& Devine, K. M. (1998). Base composition skews, replication orientation, and gene orientation in 12 prokaryote genomes. J Mol Evol 47, 691-696.

Médigue, C., Rouxel, T., Vigier, P., Henaut, A. \& Danchin, A. (1991). Evidence for horizontal gene transfer in Escherichia coli speciation. $J$ Mol Biol 222, 851-856.

Mollet, C., Drancourt, M. \& Raoult, D. (1997). rpoB sequence analysis 
as a novel basis for bacterial identification. Mol Microbiol 26, 1005-1011.

Monnet, D. \& Freney, J. (1994). Method for differentiating Klebsiella planticola and Klebsiella terrigena from other Klebsiella species. J Clin Microbiol 32, 1121-1122.

Morgan, J. A. W., Kuntzelmann, V., Tavenor, S., Ousley, M. A. \& Winstanley, C. (1997). Survival of Xenorhabdus nematophilus and Photorhabdus luminescens in water and soil. J Appl Microbiol 83, 665-670.

Morton, B. R. (1998). Selection on the codon bias of chloroplast and cyanelle genes in different plant and algal lineages. J Mol Evol 46, 449-459.

Musto, H., Romero, H. \& Rodriguez-Maseda, H. (1998). Heterogeneity in codon usage in the flatworm Schistosoma mansoni. J Mol Evol 46, 159-167.

Muto, A. \& Osawa, S. (1987). The guanine and cytosine content of genomic DNA and bacterial evolution. Proc Natl Acad Sci U S A 84, 166-169.

Nei, M. \& Gojobori, T. (1986). Simple methods for estimating the numbers of synonymous and non-synonymous nucleotide substitutions. Mol Biol Evol 3, 418-426.

Nitzan, Y., Orlovsky, K. \& Pechatnikov, I. (1999). Characterization of porins isolated from the outer membrane of Serratia liquefaciens. Curr Microbiol 38, 71-79.

Ohtaka, C. \& Ishikawa, H. (1993). Accumulation of adenine and thymine in groE-homologous operon of an intracellular symbiont. $J$ Mol Evol 36, 121-126.

Olsen, G. J. \& Woese, C. R. (1993). Ribosomal RNA: a key to phylogeny. FASEB J 7, 113-123.

Olsen, G. J., Lane, D. J., Giovannoni, S. J., Pace, N. R. \& Stahl, D. A. (1986). Microbial ecology and evolution: a ribosomal RNA approach. Annu Rev Microbiol 40, 337-365.

Olsen, G. J., Matsuda, H., Hagstrom, R. \& Overbeek, R. (1994). A tool for construction of phylogenetic trees of DNA sequences using maximum likelihood. Comput Appl Biosci 10, 41-48.

Otsuka, J., Fukuchi, S. \& Kikuchi, N. (1997). A theoretical method for evaluating the relative importance of positive selection and neutral drift from observed base changes. $J$ Mol Evol 45, 178-192.

Parales, T. E. \& Harwood, C. S. (1990). Nucleotide sequence of the gyrB gene of Pseudomonas putida. Nucleic Acids Res 18, 5880.

Pearson, W. R. \& Lipman, D. (1988). Improved tools for biological sequence comparisons. Proc Natl Acad Sci U S A 85, 2444-2448.

Philippe, H. \& Laurent, J. (1998). How good are deep phylogenetic trees? Curr Opin Genet Dev 8, 616-623.

Philippe, H. U., Sorhannus, U., Barouin, A., Perasso, R., Gasse, F. \& Adoutte, A. (1994). Comparison of molecular and paleontological data in diatoms suggests a major gap in the fossil record. J Evol Biol 7, 247-265.

Rashtchian, A., Buchman, G. W., Schuster, D. M. \& Berninger, M. S. (1992). Uracil DNA glycosylase-mediated cloning of polymerase chain reaction-amplified DNA: application to genomic and cDNA cloning. Anal Biochem 206, 91-97.

Roe, K. J., Conkel, D. \& Lydeard, C. (1997). Molecular systematics of Middle American cichlid fishes and the evolution of trophic-types in 'Cichlasoma (Amphilophus)' and 'C. (Thorichthys)'. Mol Phylogenet Evol 7, 366-376.

Saitou, N. \& Nei, M. (1987). The neighbor-joining method: a new method for reconstructing phylogenetic trees. Mol Biol Evol 4, 406-425.

Sameshima, S., Hasegawa, E., Kitade, O., Minaka, N. \& Matsumoto, T. (1999). Phylogenetic comparison of endosymbionts with their host ants based on molecular evidence. Zool Sci 16, 993-1000.

Sanderson, K. E., Hessel, A. \& Rudd, K. E. (1995). Genetic map of Salmonella typhimurium, edition VIII. Microbiol Rev 59, 241-303.

Sharp, P. M. (1997). In search of molecular darwinism. Nature 385, 111-112.

Sharp, P. M. \& Li, W.-H. (1987). The codon adaptation index -a measure of directional synonymous codon usage bias, and its potential applications. Nucleic Acids Res 15, 1281-1295.

Skovgaard, O. (1990). Nucleotide sequence of a Proteus mirabilis DNA fragment homologous to the 60K-rnpA-rpmH-dnaN-recF-gyrB region of Escherichia coli. Gene 93, 27-34.

Skovgaard, O. \& Hansen, F. G. (1987). Comparison of dnaA nucleotide sequences of Escherichia coli, Salmonella typhimurium and Serratia marcescens. J Bacteriol 169, 3976-3981.

Spröer, C., Mendrock, U., Swiderski, J., Lang, E. \& Stackebrandt, E. (1999). The phylogenetic position of Serratia, Buttiauxella and other genera of the family Enterobacteriaceae. Int J Syst Bacteriol 49, 1433-1438.

Swofford, D. L. (1998). PAUP*. Phylogenetic analysis using parsimony (*and other methods). Version 4. Sunderland, MA: Sinauer Associates. Tanaka, Y., Yamaguchi, N. \& Nasu, M. (2000). Viability of Escherichia coli $\mathrm{O} 157: \mathrm{H} 7$ in natural river water determined by the use of flow cytometry. J Appl Microbiol 88, 228-236.

Tateno, Y., Takezaki, N. \& Nei, M. (1994). Relative efficiencies of the maximum-likelihood, neighbor-joining and maximum-parsimony methods when substitution rate varies with site. Mol Biol Evol 11, 261-277.

Ursua, P. R., Unzaga, M. J., Melero, P., Iturburu, I., Ezpeleta, C. \& Cisterna, R. (1996). Serratia rubidaea as an invasive pathogen. J Clin Microbiol 34, 216-217.

Van de Peer, Y., Rensing, S. A., Maier, U. G. \& De Wachter, R. (1996). Substitution rate calibration of small subunit ribosomal RNA identifies chlorarachniophyte endosymbionts as remnants of green algae. Proc Natl Acad Sci U S A 93, 7732-7736.

Venkateswaran, K., Dohmoto, N. \& Harayama, S. (1998). Cloning and nucleotide sequence of the gyr B gene of Vibrio parahaemolyticus and its application in detection of this pathogen in shrimp. Appl Environ Microbiol 64, 681-687.

Venkateswaran, K., Moser, D. P., Dollhopf, M. E. \& 10 other authors (1999). Polyphasic taxonomy of the genus Shewanella and description of Shewanella oneidensis sp. nov. Int J Syst Bacteriol 49, 705-724.

Vuddhakul, V., Nakai, T., Matsumoto, C., Oh, T., Nishino, T., Chen, C.-H., Nishibuchi, M. \& Okuda, J. (2000). Analysis of $\operatorname{gyr} B$ and toxR gene sequences of Vibrio hollisae and development of $g y r B$ - and toxRtargeted PCR methods for isolation of $V$. hollisae from the environment and its identification. Appl Environ Microbiol 66, 3506-3514.

Wang, J. C. (1996). DNA topoisomerases. Annu Rev Biochem 65, 635-692.

Wang, Y. \& Zhang, Z. (2000). Comparative sequence analyses reveal frequent occurrence of short segments containing an abnormally high number of non-random base variations in bacterial rRNA genes. Microbiology 146, 2845-2854.

Wayne, L. G., Brenner, D. J., Colwell, R. R. \& 9 other authors (1987). International Committee on Systematic Bacteriology. Report of the ad hoc committee on reconciliation of approaches to bacterial systematics. Int J Syst Bacteriol 37, 463-464.

Woese, C. R. (1987). Bacterial evolution. Microbiol Rev 51, 221-271.

Yamada, S., Ohashi, E., Agata, N. \& Venkateswaran, K. (1999). Cloning and nucleotide sequence analysis of gyrB of Bacillus cereus, $B$. thuringiensis, $B$. mycoides, and $B$. anthracis and their application to the detection of B. cereus in rice. Appl Environ Microbiol 65, 1483-1490.

Yamamoto, S. \& Harayama, S. (1995). PCR amplification and direct sequencing of $\operatorname{gyr} B$ genes with universal primers and their application to the detection and taxonomic analysis of Pseudomonas putida strains. Appl Environ Microbiol 61, 1104-1109.

Yamamoto, S. \& Harayama, S. (1996). Phylogenetic analysis of Acinetobacter strains based on the nucleotide sequence of $\operatorname{gyr} B$ genes and on the amino acid sequences of their products. Int $J$ Syst Bacteriol 46, 506-511.

Yamamoto, S. \& Harayama, S. (1998). Phylogenetic relationships of Pseudomonas putida strains deduced from the nucleotide sequences of gyr B, rpoD, and 16S rRNA genes. Int J Syst Bacteriol 48, 813-819. 
Yamamoto, S., Bouvet, P. J. M. \& Harayama, S. (1999). Phylogenetic structures of the genus Acinetobacter based on the $\operatorname{gyr} B$ sequences: comparison with the grouping by DNA-DNA hybridization. Int $J$ Syst Bacteriol 49, 87-95.

Yang, Z. (1996). Among-site rate variation and its impact on phylogenetic analyses. Trends Ecol Evol 11, 367-372.
Yang, Z. (1997). PAML: a program package for phylogenetic analysis by maximum likelihood. CABIOS 13, 555-556.

Yap, W. H., Zhang, Z. \& Wang, Y. (1999). Distinct types of rRNA operons exist in the genome of the actinomycete Thermomonospora chromogena and evidence for horizontal transfer of an entire rRNA operon. J Bacteriol 181, 5201-5209. 